\title{
The pressure injury predictive model: A framework for hospital-acquired pressure injuries
}

\author{
Dana Tschannen PhD, RN, Clinical Associate Professor (D) | Christine Anderson PhD, RN, \\ Clinical Associate Professor
}

School of Nursing, University of Michigan, Ann Arbor, MI, USA

\section{Correspondence}

Dana Tschannen, School of Nursing, University of Michigan, 400 N. Ingalls, Room 4152; Ann Arbor, MI 48109, USA.

Email:djvs@umich.edu

\begin{abstract}
Background: Despite decades of research, pressure injuries continue to be a source of significant pain and delayed recovery for patients and substantial quality and cost issues for hospitals. Consideration of the current thinking around pressure injury risk must be evaluated to improve risk assessments and subsequent nursing interventions aimed at reducing hospital-acquired pressure injuries.

Design: This is a discursive paper using Walker and Avant's (2005) theory synthesis framework to examine the relevance of existing pressure injury models as they align with the current literature.

Methods: PubMed and CINAHL indexes were searched, first for conceptual models and then for pressure injury research conducted on hospitalised patients for the years 2006-2016. A synthesis of the searches culminated into a new pressure injury risk model.

Conclusions: Gaps in previous models include lack of attention to the environment, contributing episode-of-care factors and the dynamic nature of injury risk for patients. Through theory synthesis, the need for a new model representing the full risk for pressure injury was identified. The Pressure Injury Predictive Model is a representation of the complex and dynamic nature of pressure injury risk that builds on previous models and addresses new patient, contextual and episode-of-care process influences. The Pressure Injury Predictive Model (PIPM) provides a more accurate picture of the complexity of contextual and process factors associated with pressure injury development.

Relevance to Clinical Practice: Using the PIPM to determine risk can result in improved risk identification. This information can be used to implement targeted, evidence-based pressure injury prevention interventions specific to the patient risk profile, thus limiting unwarranted and unnecessary care.
\end{abstract}

\section{KEYWORDS}

hospitalisation, nursing theory, predictive model, pressure injury, pressure ulcer, theory synthesis 


\section{AIM}

The aim of this paper is to describe the process of theory synthesis and the development of a framework, the Pressure Injury Predictive Model (PIPM), indicating the complex and dynamic nature of PI risk for hospitalised adult patients.

\section{BACKGROUND}

Patients who develop a hospital-acquired pressure injury (HAPI) are 2.8 times more likely to die during their hospital stay $(p<.001)$ and 1.69 times more likely to die within 30 days after discharge $(p<.001)$ and are subject to significant amounts of pain and suffering, delayed functional recovery and increased length of hospital stay (Lyder et al., 2012; Thomas, Goode, Tarquine, \& Allman, 1996). According to the Agency for Healthcare Research and Quality (AHRQ) National Scorecard Data on hospital-acquired conditions, over 1 million patients in the USA develop a pressure injury while in the hospital. Although there was an encouraging $23 \%$ decline in the number of patients affected between 2010-2014, rates increased $10 \%$ between 2014-2016 (AHRQ, 2018). In addition to the adverse impact on patients (Lyder et al., 2012), recent estimates of care-related costs associated with HAPIs amount to approximately $\$ 25,990$ USD per stay (Spector, Limcangco, Owens, \& Steiner, 2016). Aggregate estimates are reported to be a staggering $\$ 11$ billion (USD) annually (Russo, Steiner, \& Spector, 2006).

A pressure injury $(\mathrm{PI})$ is defined as any area of skin or underlying tissue that has been damaged because of intense or prolonged pressure in combination with shear (National Pressure Ulcer Advisory Panel, 2016). The idea that PI is a nursing-sensitive indicator dates back to Florence Nightingale, who described bedsores as "generally the fault not of the disease, but of the nursing" (Nightingale, 1859, p. 6). PIs were considered preventable, primarily the result of unrelieved pressure upon bony prominences. Some of the earliest research on PI was done with canine models. For example, Kosiak, Kubicek, Olson, Danz, and Kottke (1958) found an inverse relationship between pressure applied and length of time, such that there was a high degree of tissue susceptibility at low pressure over prolonged periods and higher pressures for shorter timeframes. Microscopic examination of tissue post-pressure application of $60 \mathrm{mmHg}$ for one hour showed cellular infiltration, extravasation and hyaline degeneration, with muscular necrosis and venous thrombosis occurring with higher pressure for longer periods of time (Kosiak et al., 1958). This early work gave foundational support for many of the conceptual frameworks developed for identifying a patient's risk for PI, since pressure was identified as the primary cause of what were then called "bedsores" or decubitus ulcers.

Decades of research have resulted in the identification of $\mathrm{PI}$ risk factors, interventions to reduce such risk, and evidence-based treatment plans for those who unfortunately develop PIs. These studies illustrate some of the complex systems characteristics of PIs. Specifically, these include the heterogeneity of individual and

\section{What does this paper contribute to the wider global clinical community?}

- This paper critically reflects on our understanding of risk for PI development in hospitalised patients, including how risk is represented in current conceptual frameworks.

- Evidence suggests the need for a more accurate, encompassing model that reflects risk for PI.

- The Pressure Injury Predictive Model (PIPM) is the first model to fully capture the complexity and dynamic nature of many PI risk factors, including environmental and episode-of-care factors.

- Use of the PIPM can result in improved identification of risk that can lead to more targeted evidence-based interventions.

environmental factors, the dynamics of the processes and resulting feedback loops involved, and the nonlinear contributing factors at multiple levels. Simply put, PI development is complex and dynamic and involves the interaction of patient, environmental and care process-related factors. In this discursive paper, we examine this complexity as it is reflected in PI conceptual frameworks and current literature.

\section{DESIGN}

The original intention of this work was to outline the most recent evidence suggesting factors predictive of hospital-acquired PIs and their alignment with PI risk frameworks. A discursive paper provides a formal mechanism for examining a particular issue or problem, using a for/against, opinion or solution-focused framework. Using Walker and Avant's (2005) theory synthesis method, the need for a new model more accurately representing the complexity in PI risk was made clear. Thus, what follows is a discursive paper suggesting solutions to the identified problem (e.g. failure of current models to reflect factors predictive of hospital-acquired $\mathrm{PI}$ ).

\section{4 | METHOD}

According to Walker and Avant (2005), a primary purpose of theory synthesis is "to represent factors that proceed or influence a particular event (pg. 138)." The theory synthesis process was used to develop the PIPM and includes the following steps:

1. Specifying focal concepts to serve as anchors for the synthesised theory

2. Reviewing the literature to identify factors related to the focal concepts and to specify the nature of relationships; 
3. Organising concepts and statements into an integrated and efficient representation of the phenomena of interest (Walker \& Avant, 2005).

The first step in the process involved the specification of focal concepts associated with $\mathrm{PI}$, which subsequently provided the foundation for the synthesised theory. For this step, a literature search using PubMed and CINAHL was conducted to identify conceptual models for predicting pressure injury. To be included, the models needed to provide a framework specific for PI development; thus, models focused more broadly on skin alterations were not included.

The second step in the theory synthesis process involved a more in-depth review of the literature to determine the empirical evidence for relationships among the focal constructs and concepts identified in step 1. For this reason, a narrative review was conducted using $\mathrm{MeSH}$ and keywords including pressure ulcers/injuries, risk factor and surgical/hospitalised patients in two search engines (PubMed and $\mathrm{CINAHL)}$. The primary inclusion criteria included the following: (a) research studies conducted between 2006-2016 and English language; and (b) sample contained adult ( $>18$ years of age) patients. Studies sampling paediatric patients were excluded from the review due to the uniqueness of risk for PI among the two patient populations. The outcome of interest was HAPIs, and thus, studies with the primary purpose of predicting the development of HAPIs were included.

The final step in theory synthesis, organisation of concepts and statements into an integrated representation, included a review of each of the concepts identified in the conceptual model synthesis and empirical evidence. All of the concepts were listed and categorised into clusters. Relational statements were developed among the concepts/clusters to create the graphical representation of the new integrated PIPM.

\section{5 | CONCLUSION}

\section{1 | Step 1: Specifying focal concepts to serve as anchors for the synthesised theory}

Five conceptual models met the inclusion criteria. Concepts and constructs in each of the models were identified and mapped to determine the similarities and differences among the respective models (Table 1).

\subsection{1 | Model overview}

One of the earliest conceptual models developed for $\mathrm{PI}$ research was developed by Braden and Bergstrom (1987). According to the model, pressure-as determined by mobility, activity, sensory perception-in combination with both extrinsic (e.g. moisture, friction, shear) and intrinsic factors (e.g. nutrition, age, arteriolar pressure and other factors) related to tissue tolerance impact PI development.
The intensity and duration of pressure and susceptibility of the tissue determined the level of risk for PI formation. Defloor (1999) expounded upon Braden and Bergstrom's work, arguing that tissue tolerance cannot independently cause a PI. Rather, Defloor (1999) considered tissue tolerance as an intermediate variable, which was further delineated as tissue tolerance for pressure and tissue tolerance for oxygen. According to Defloor (1999), tissue tolerance for pressure refers to factors that "change the capacity of the tissue to redistribute pressure (p. 211)." Factors that further impact tissue tolerance are those affecting oxygen distribution and tissue oxygen needs, which Defloor terms tissue tolerance for oxygen. He further subcategorised pressure as (a) compression force (e.g. perpendicular pressure to the tissue) and (b) shearing force (e.g. parallel pressure to the tissue). The model represented a bidirectional relationship between both types of pressure, mediated by tissue tolerance, as the determinant of PI risk.

In alignment with earlier PI conceptual models, Benoit and Mion (2012) created a conceptual model for PI aetiology in critically ill patients. Like Braden and Bergstrom (1987) and Defloor (1999), they acknowledged pressure and tissue tolerance as the primary constructs associated with PI development. Specifically, the authors posited that tissue tolerance, including intrinsic and extrinsic factors, moderated the effect of pressure on PI development. Recently, Coleman et al. (2014) and García-Fernández, Agreda, Verdú, and Pancorbo-Hidalgo (2014) have considered other factors as contributory to PI development. Coleman et al. (2013) conducted a systematic review and consensus study to identify the critical determinants of PI development. Based on the results of this work, a new conceptual model was developed which recognised PI development as directly related to mechanical boundary conditions and the susceptibility and tolerance of the individual (Coleman et al., 2014). Likewise, García-Fernández et al. (2014) diverged from earlier PI models by identifying only pressure and shear forces as the primary factors associated with PI development. Forces of pressure, according to the model, include dimensions that reduce repositioning and sensory perception. They considered shear force an independent predictor, indicating that the presence of shearing, even with lower pressure, may cause a PI. Tissue tolerance was deemed a predisposing factor but not aetiologic.

\subsection{2 | Model synthesis}

The conceptual models reviewed were remarkably similar in terms of major constructs and concepts associated with PI development, although the relational statements varied between the models (Table 1). Pressure, although being defined through various concepts within the respective models, played a primary role in PI development among the conceptual models. Pressure can be impacted by a variety of factors, including mobility, activity, shear, nutrition and perfusion. Individuals who had reduced activity/mobility, inadequate nutrition or poor perfusion were at greater risk for PIs. The specific intensity and duration of pressure needed for PI development was 
TABLE 1 Mapping of constructs in current pressure injury risk models

\begin{tabular}{|c|c|c|c|c|c|}
\hline Construct & $\begin{array}{l}\text { Braden and } \\
\text { Bergstrom (1987) }\end{array}$ & DeFloor (1999) & $\begin{array}{l}\text { Garcia-Fernández, } \\
\text { Agreda, Verdu, \& } \\
\text { Pancorbo-Hidalgo } \\
\text { (2014) }\end{array}$ & $\begin{array}{l}\text { Benoit and Mion } \\
(2012)\end{array}$ & Coleman et al. (2013) \\
\hline Pressure & $\begin{array}{l}\text { Mobility } \\
\text { Activity } \\
\text { Sensory perception }\end{array}$ & $\begin{array}{l}\text { Compression force: intensity } \\
\text { (support, posture, body } \\
\text { build, medical/nursing } \\
\text { interventions); duration (pain } \\
\text { reaction, pain sensitivity, } \\
\text { mobility/activity, medical/ } \\
\text { nursing interventions) } \\
\text { Shearing force: intensity } \\
\text { (support, posture, } \\
\text { maceration, friction); } \\
\text { duration (pain reaction, } \\
\text { pain sensitivity, mobility/ } \\
\text { activity, medical/nursing } \\
\text { interventions) }\end{array}$ & $\begin{array}{l}\text { Capacity for } \\
\text { repositioning } \\
\text { Sensory perception }\end{array}$ & $\begin{array}{l}\text { Mobility } \\
\text { Activity } \\
\text { Sensory } \\
\text { perception }\end{array}$ & $\begin{array}{l}\text { *deemed Mechanical } \\
\text { Boundary Conditions } \\
\text { Magnitude and } \\
\text { duration of load; } \\
\text { Type of load (pressure, } \\
\text { friction, shear) } \\
\text { Risk factors: } \\
\text { immobility, poor } \\
\text { sensory perception } \\
\text { and response }\end{array}$ \\
\hline Shear & $\begin{array}{l}\text { Aligned with tissue } \\
\text { tolerance }\end{array}$ & $\begin{array}{l}\text { Aligned as a component of } \\
\text { pressure }\end{array}$ & $\begin{array}{l}\text { Shear forces (e.g. } \\
\text { opposite/parallel } \\
\text { sliding of tissue) }\end{array}$ & $\begin{array}{l}\text { Aligned with tissue } \\
\text { tolerance }\end{array}$ & $\begin{array}{l}\text { Aligned as a component } \\
\text { of pressure }\end{array}$ \\
\hline $\begin{array}{l}\text { Tissue } \\
\text { tolerance }\end{array}$ & $\begin{array}{l}\text { Extrinsic factors: } \\
\text { moisture, friction, } \\
\text { shear } \\
\text { Intrinsic factors: } \\
\text { nutrition, age, } \\
\text { arteriolar pressure, } \\
\text { other (interstitial } \\
\text { fluid flow, emotional } \\
\text { stress, smoking, skin } \\
\text { temperature) }\end{array}$ & $\begin{array}{l}\text { Tissue tolerance for pressure: } \\
\text { tissue mass, age dehydration, } \\
\text { protein/Vit C deficiency, } \\
\text { corticosteroid, stress } \\
\text { Tissue tolerance for oxygen: } \\
\text { O2 Needs (temperature); } \\
\text { O2 Supply (medication, } \\
\text { protein deficiency, smoking, } \\
\text { diseases (O2 supply, reactive } \\
\text { hyperaemia, vascular } \\
\text { occlusion), blood pressure }\end{array}$ & $\begin{array}{l}\text { Considered a } \\
\text { coadjuvant } \\
\text { (predisposing factor } \\
\text { that can influence } \\
\text { or induce the } \\
\text { development of lesion) }\end{array}$ & $\begin{array}{l}\text { Extrinsic factors: } \\
\text { moisture, } \\
\text { friction/shear } \\
\text { Intrinsic factors: } \\
\text { metabolic } \\
\text { supply and } \\
\text { demand, } \\
\text { pressure } \\
\text { distribution } \\
\text { capacity, threats } \\
\text { to skin integrity }\end{array}$ & $\begin{array}{l}\text { *Deemed individual } \\
\text { susceptibility and } \\
\text { tolerance } \\
\text { Physiology and } \\
\text { repair; transport and } \\
\text { thermal properties; } \\
\text { mechanical } \\
\text { properties of tissue } \\
\text { (stiffness strength); } \\
\text { geometry (size/shape } \\
\text { of different tissue } \\
\text { layers) of the tissue } \\
\text { and bones } \\
\text { Risk factors: skin/ } \\
\text { Pl status, poor } \\
\text { perfusion, poor } \\
\text { nutrition, diabetes, } \\
\text { moisture, low } \\
\text { albumin }\end{array}$ \\
\hline Other & & & $\begin{array}{l}\text { Other adjuvant } \\
\text { factors include tissue } \\
\text { nutrition, oxygen } \\
\text { alterations, skin } \\
\text { alterations }\end{array}$ & & \\
\hline
\end{tabular}

dependent on other factors, including the ability of tissue to tolerate the intensity and duration.

Like pressure, tissue tolerance was significant in each of the models reviewed, although interpretation varied. Four of the five models denoted concepts of tissue tolerance, such as moisture, friction, smoking, skin temperature and fluid volume, respectively. Despite inclusion of tissue tolerance as a construct, differences in the relational role varied among models. For example, Benoit and Mion (2012) identified tissue tolerance as a moderator between pressure and PI, whereas Coleman et al. (2014) described a bidirectional relationship between individual susceptibility (e.g. tissue tolerance) and mechanical boundary conditions (e.g. pressure).
The final construct found in all models was shear. Shear was primarily considered in association with pressure (Coleman et al., 2014; DeFloor, 1999) or tissue tolerance (Benoit \& Mion, 2012; Braden \& Bergstrom, 1987). Only Garcia-Fernández et al. (2014) recognised shear as an independent construct. The relationship between shear and PI development warrants further study.

\subsection{3 | Summary}

Despite the similarities, it is clear from the review that further consideration of the risks of PI development must be explored. 
Conceptual models to date primarily represent only one-directional relationships, including a smattering of risk factors, certainly not all of the factors that are predictive of PI. For example, thus far, the roles that evolving care processes and environmental factors may play in PI development are not included in current conceptual models. Similarly, model developers to date have not considered the impact of varying combinations of risk, which could exponentially influence levels of PI risk. For this reason, the next phase of work included a review of the current evidence about factors that are predictive of $\mathrm{PI}$ development.

\subsection{Step 2: Reviewing the literature to identify factors related to the focal concepts and to specify the nature of relationships}

A total of 662 distinct publications were found during the initial search. The research team appraised titles and abstracts, eliminating 305 articles after title review and an additional 162 articles after abstract review. Full text articles were obtained and reviewed to assure alignment with the primary purpose of risk prediction for HAPI development. Upon this final review, only 59 studies met all the inclusion criteria (Figure 1). Several studies were excluded because the dependent variable was not HAPI (e.g. community-acquired PIs) or the purpose was on the evaluation of specific nursing interventions to reduce PI risk (e.g. mattress type, positioning and mobility protocols, nutrition interventions), rather than predicting the development of a HAPI.

For each of the remaining studies, the levels of evidence were examined and categorised according to Melnyk and FineoutOverholt (2011), one of a number of evidence rating systems used by academics, researchers and clinicians to evaluate the strength of the evidence. Levels range from level 1 (systematic review and meta-analysis of randomised controlled trials or clinical guidelines based on systematic reviews or meta-analyses)-level 7 (e.g. expert opinion); the higher the level of evidence, the greater the strength in the identified results. For the studies included in this review, the majority were case-control or cohort studies (level $4, n=21$ ) and single descriptive or qualitative studies (level $6, n=33$ ). There were two meta-analyses (level 1 ) and three systematic reviews (level 5).

The focal constructs and concepts for PI risk, as identified in the literature, will be described under the following headings: pressure, tissue tolerance and shear. In an effort to synthesise the studies, the total number of studies including each concept as an independent variable was determined. Subsequently, the findings for each study were reviewed to determine whether the specific concept was deemed a significant predictor of $\mathrm{PI}$, in order to compute a percentage reflecting the frequency of significance (e.g. number of studies with a significant finding for the specified construct divided by the

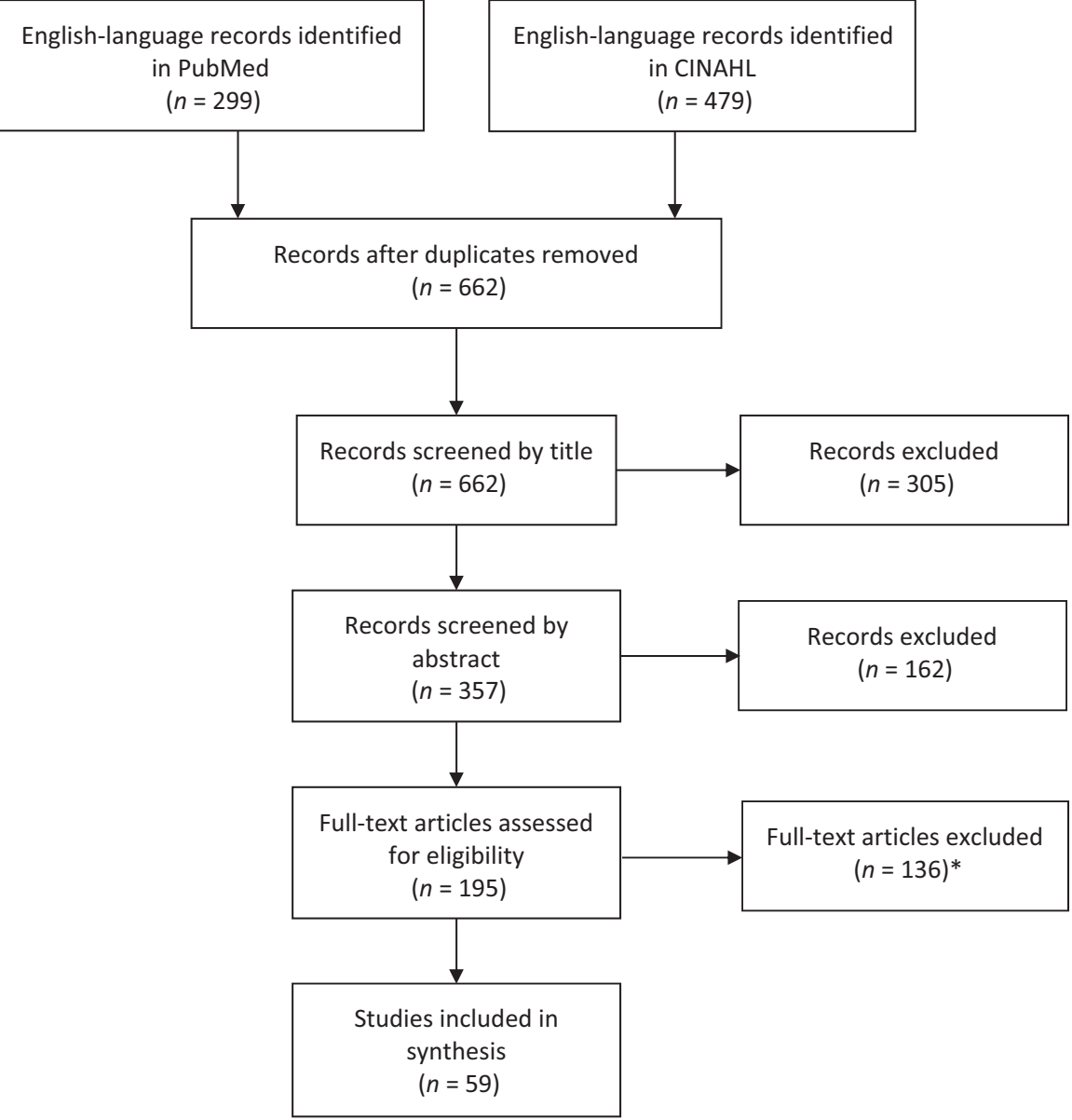

FIGURE 1 Literature flow diagram for years 2006-2016. *Articles excluded when the dependent variable was not hospital acquired pressure injury or the purpose was not the prediction of pressure injury 
total number of studies evaluating the specific construct). Details of the constructs, concepts, indicators and relationships to PI development are shown in Table 2.

\subsection{1 | Pressure}

Factors that affect the duration and intensity of pressure have been the focus of research designed to test the extent to which they contribute to PI development. A total of 24 studies evaluated concepts associated with pressure, including mobility/activity, sensory perception, body posture/stature, pain and equipment type (e.g. mattress type, medical devices) (Table 3). Of the studies reviewed, indicators of mobility ( $80 \%, n=16$ of 20 studies evaluating mobility found it to be a significant predictor) and activity (62\%, $n=8$ of 13 studies) were significantly associated with PI development, such that limitations in mobility and activity resulted in greater risk for PIs (Table 2). Pain and sensory perception were evaluated less frequently; however, results show that these concepts are related to HAPI development. Specifically, lower sensory perception, which included an inhibited sense of pain in one study, resulted in an increased risk for HAPI. Two studies directly examined the association of pain and PIs, both of which found significant positive relationships with higher pain levels resulting in an increased risk for HAPI (Rao, Preston, Strauss, Stamm, \& Zalman, 2016; Skogestad et al., 2017). The evidence did not substantiate body posture and stature, initially identified as a focal concept in the model presented by DeFloor (1999). No significant relationship was identified in any of the reviewed studies in which HAPI was the outcome (Kaitani, Tokunaga, Matsui, \& Sanada, 2010; Tsaousi et al., 2014; Yoshimura et al., 2015). Medical devices, such as endotracheal tubes, faecal diversion devices, tracheostomies and face masks, were found to put patients at greater risk for HAPI in two of three studies (Black et al., 2010; Bly, Schallom, Sona, \& Klinkenberg, 2016; Slowikowski \& Funk, 2010). Black et al. (2010) reported that patients with medical devices were 2.4 times more likely to develop a HAPI than those without such devices. Furthermore, a significant association between hospital mattress type and HAPI development was found in two of three studies reviewed (Bly et al., 2016; Kaitani et al., 2010; Tescher, Branda, Byrne, \& Naessens, 2012).

\subsubsection{Tissue tolerance}

According to current models, tissue tolerance, conceptually defined by Braden and Bergstrom (1987) as the ability of the skin and supporting structures to endure pressure without complications, is a primary construct in determining a patient's risk for Pls. Of the studies included in the narrative review, 41 studies examined a concept associated with tissue tolerance: presence of certain comorbidities, age, body mass index (BMI), moisture, nutrition, oxygenation and perfusion (Table 3 ). Higher rates of HAPIs have been found in patients with several chronic conditions including diabetes mellitus (Delmore, Lebovits, Suggs, Rolnitzky, \& Ayello, 2015; Liu, He, \& Chen, 2012; Nassaji, Askari, \& Ghorbani, 2014), pulmonary diseases (Bly et al., 2016), cardiovascular diseases (Cox $\&$ Roche, 2015), malignant tumours (Rao et al., 2016) and renal/ liver disease (O'Brien, Shanks, Talsma, Brenner, \& Ramachandran, 2014). Of the studies including chronic conditions as a predictor of HAPIs, 74\% (23 of 31 studies) noted a significant increase in risk with the presence of the chronic condition (Table 2). Increase in age was consistently shown to be a significant predictor of HAPI (66\%, $n=29$ of 44 studies); however, BMI was only a significant predictor in $45 \%$ of the studies included in the literature review ( $n=10$ of 22). Specifically, those with extreme BMls (e.g. morbid obesity or underweight) were more likely associated with HAPI development. Weight was only related to HAPIs in $21 \%$ of the studies that included it as an independent variable ( $n=3$ of 14). Evidence for including nutrition as predictors of HAPI is stronger, with $78 \%$ ( $n=18$ of 23 ) of studies noting a significant relationship. Albumin levels, an indicator of nutrition status, were found to have a significant negative relationship with HAPI development in $69 \%$ ( $n=9$ of 13 ) of the studies reviewed, and glucose levels were a significant predictor in both studies examining the relationship (e.g. higher glucose levels associated with increased risk). Patients who required support for oxygenation via mechanical ventilation, facemask and nasal cannula were consistently found to be at higher risk for HAPIs (70\%, $n=7$ of 10 studies). Any form of oxygenation support during a patient stay or use of bronchodilators increased the risk for PI development, with some studies finding a greater than fivefold increase in risk among patients with oxygen support. Similarly, studies evaluating the impact of perfusion on Pls found significant relationships (75\%, $n=12$ of 16$)$. For example, the use of vasopressors during the patient's stay resulted in up to an 8 times increase in risk for PI $(66 \%, n=6$ of 9 studies). Laboratory values used as proxy measures for perfusion were found to be mixed in terms of their usefulness for predicting HAPI development. Lower haemoglobin levels were associated with an increased risk for HAPI in $55 \%$ ( $n=6$ of 11 ) of the reviewed studies, while haematocrit values were less predictive (20\%, $n=1$ of 5$)$. Temperature, also used as a measure for perfusion, was shown to be a significant predictor for HAPI in $71 \%$ ( $n=5$ of 7 ) of studies reviewed. Like BMI, extremes in temperature (low or high) increase HAPI risk. Finally, moisture, measured as incontinence, excessive moisture or oedema or via the moisture Braden subscore, was found to be a significant predictor of HAPIs in $56 \%$ of the studies reviewed ( $n=13$ of 23 ) (Table 2). Patients exhibiting excessive moisture, via diaphoresis, incontinence or weeping oedema, were shown to be at an increased risk for HAPI.

\subsection{3 | Shear}

García-Fernández et al. (2014) identified shear as an independent focal concept. According to the National Pressure Ulcer Advisory 


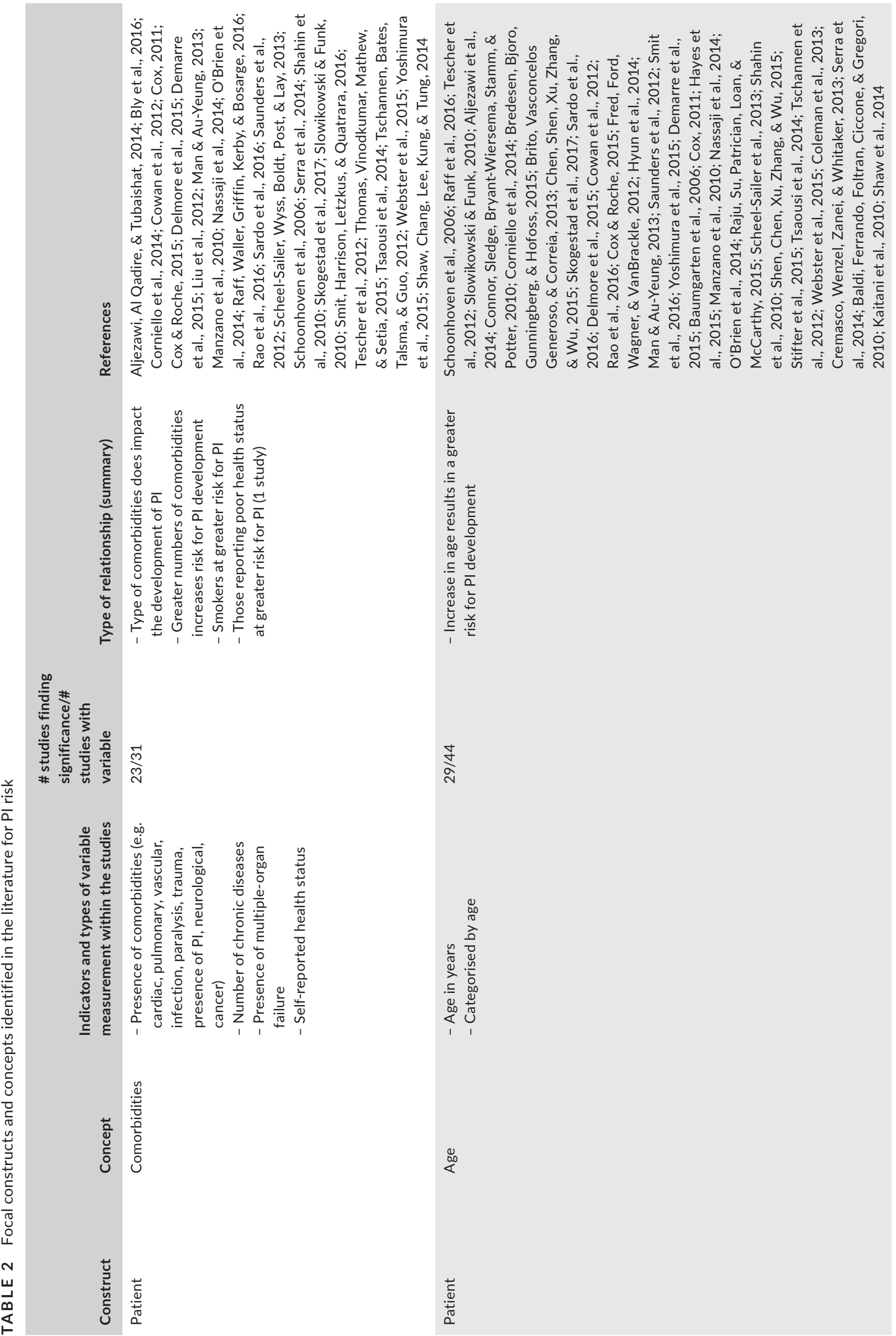




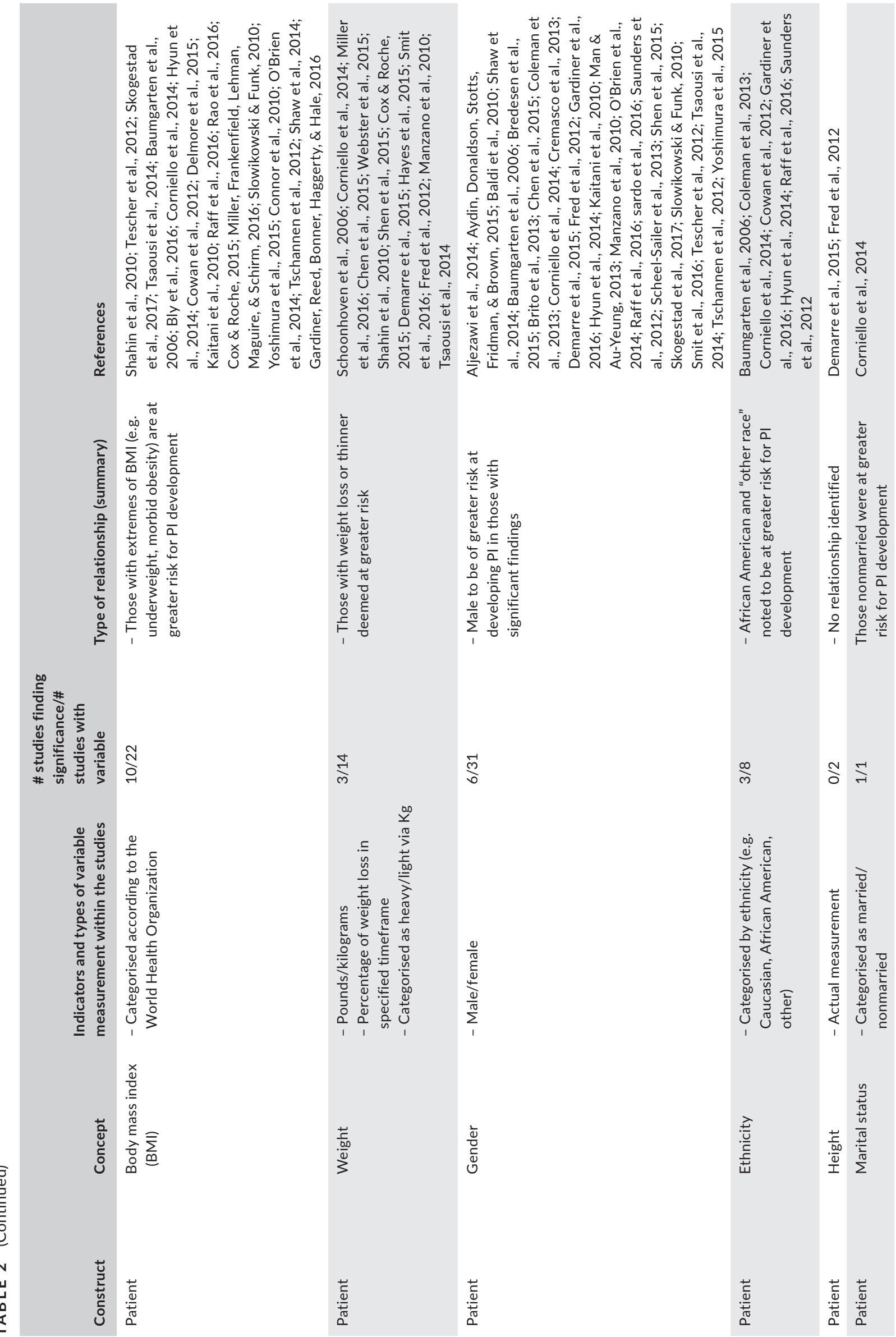



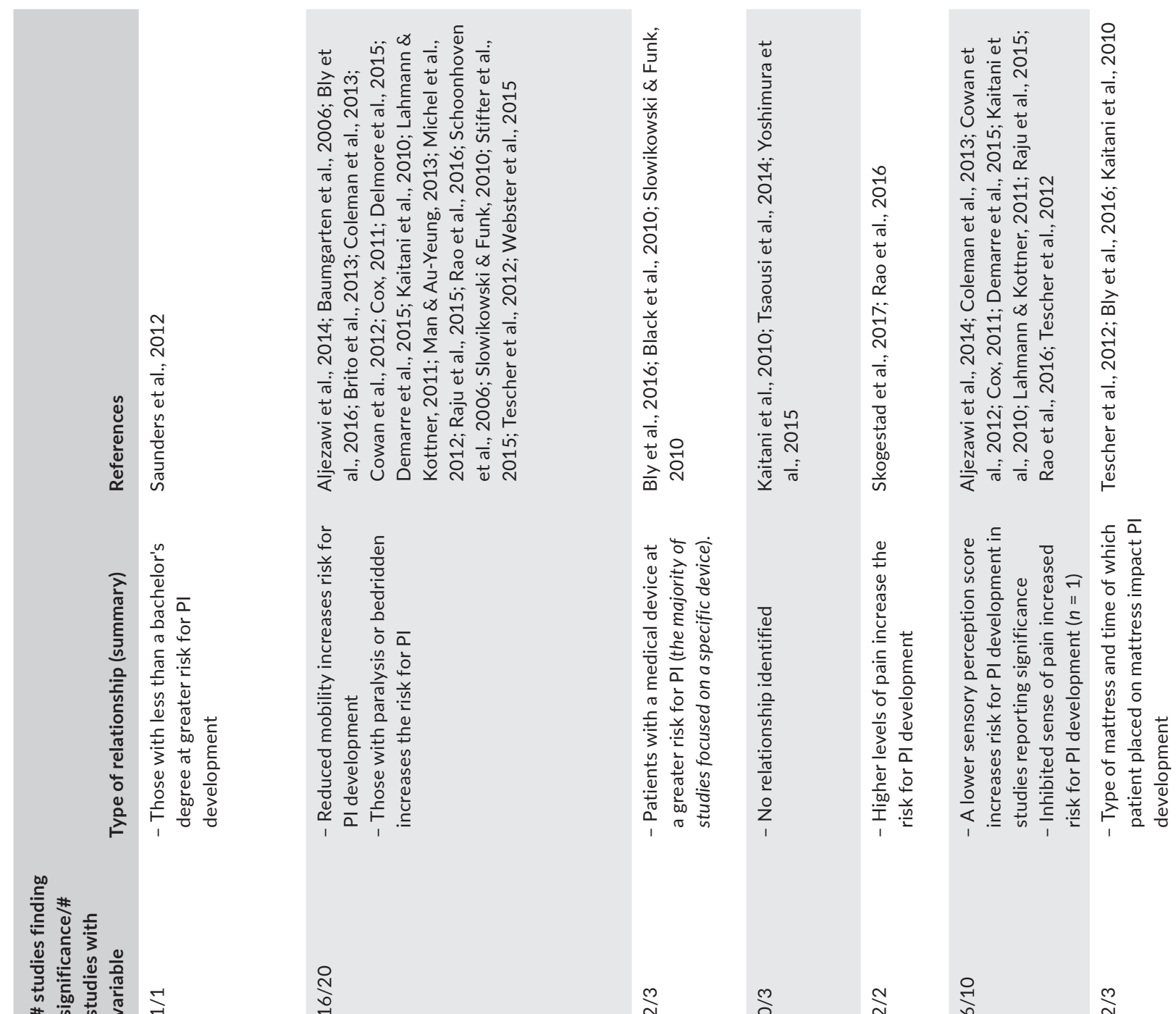

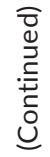

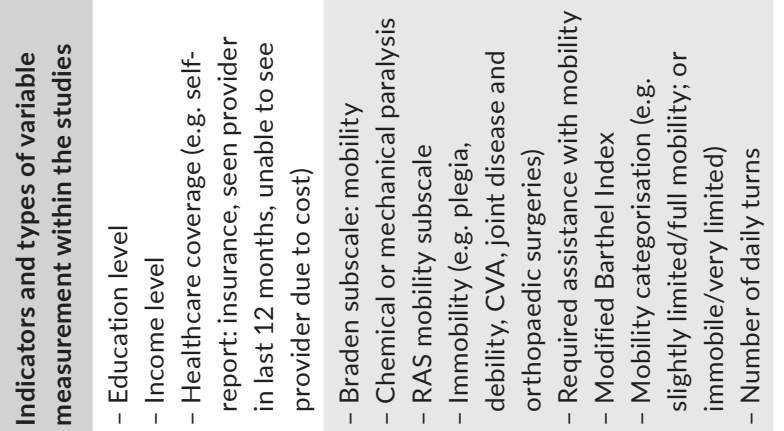

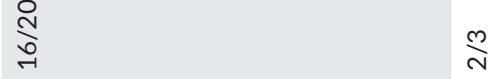
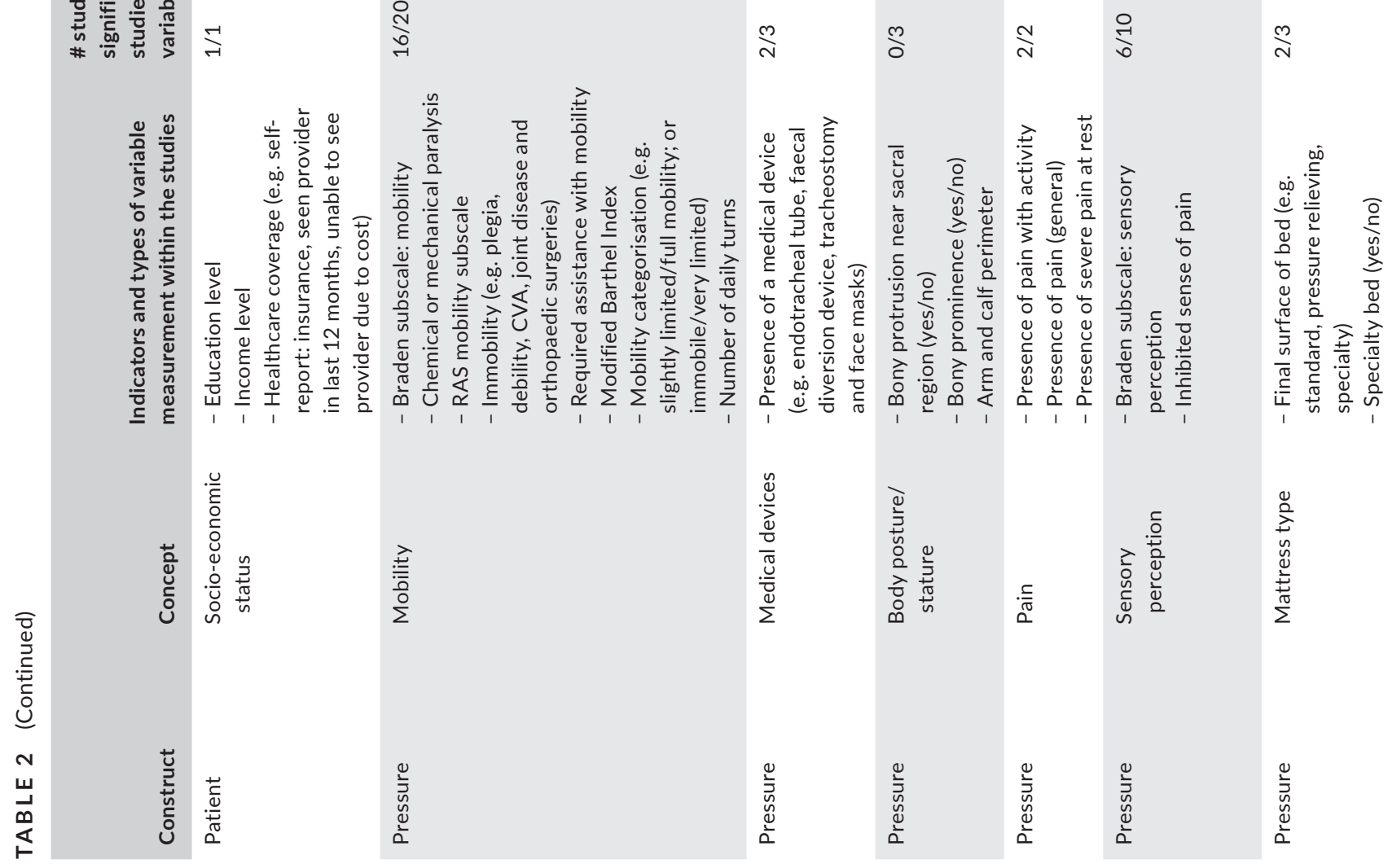

ปั 


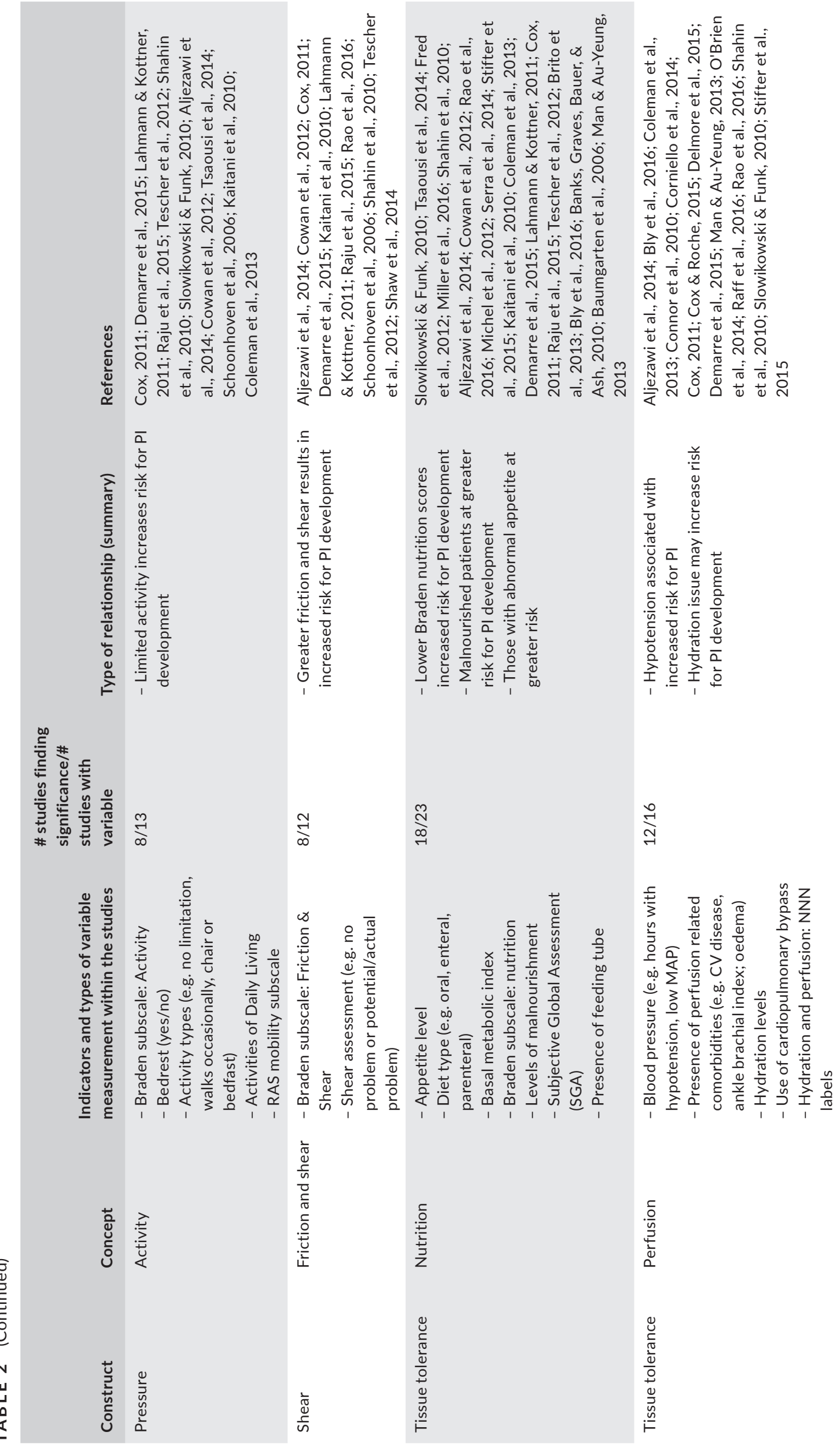



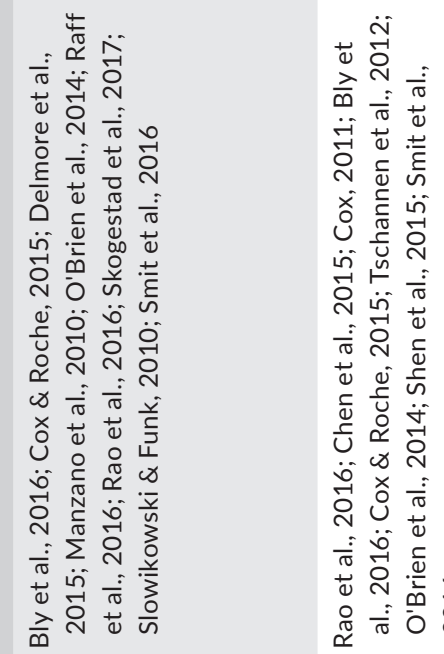

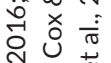

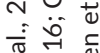

त्र

茂
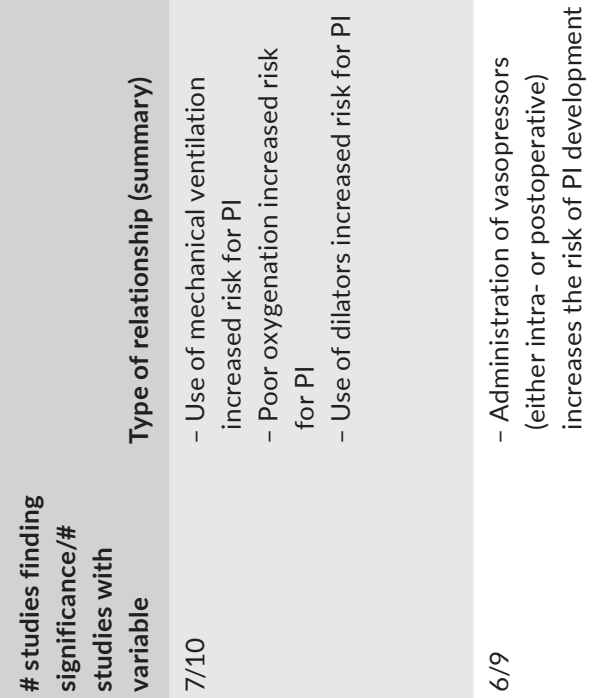

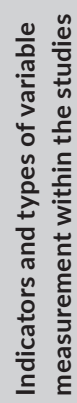

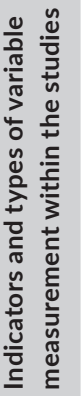

a

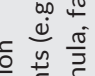

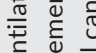

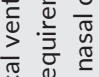

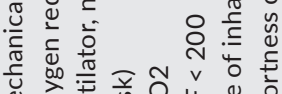

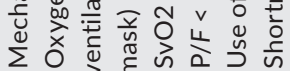

$\frac{a}{3}$

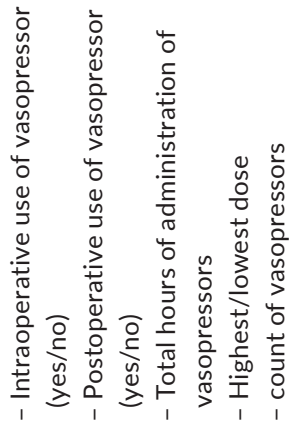

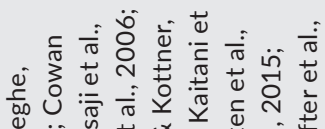

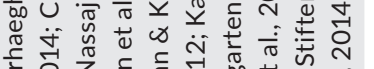

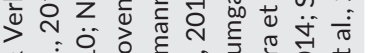

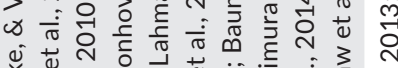

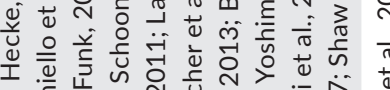

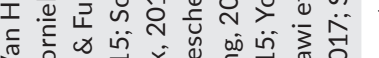

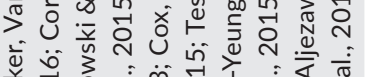

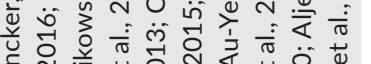

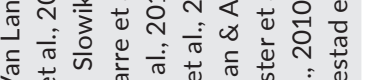

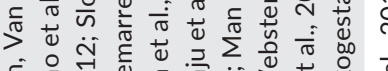

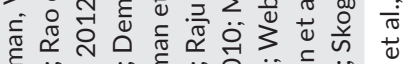

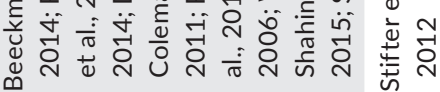
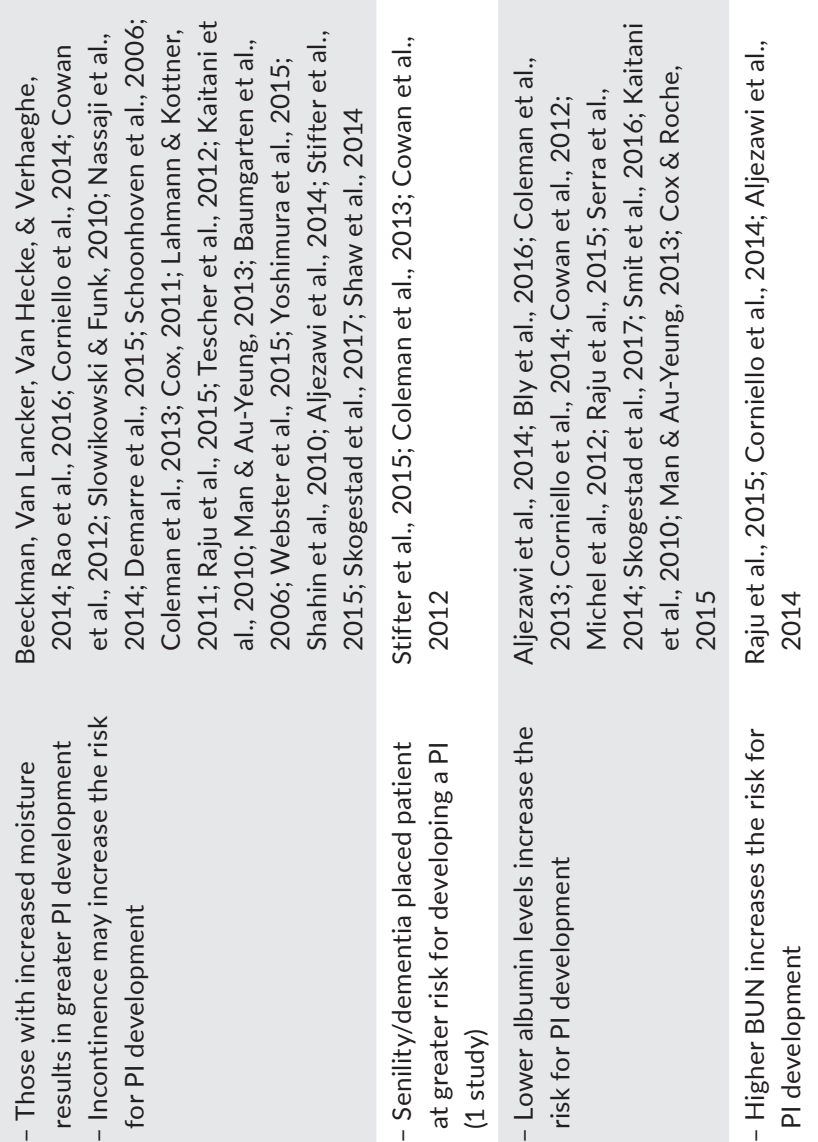

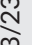

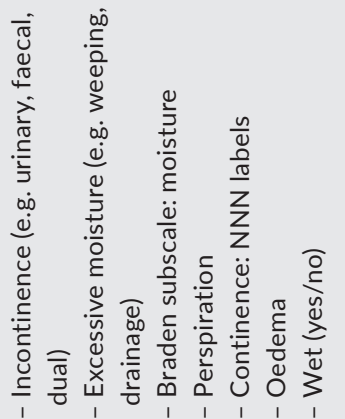

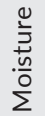

$\stackrel{m}{\rightarrow} \quad \stackrel{m}{a}$

$\stackrel{m}{\text { s }}$
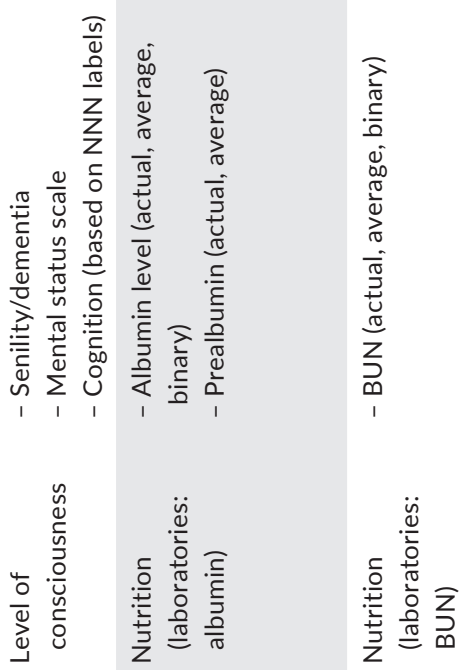

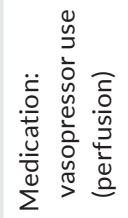

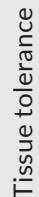

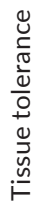

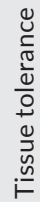

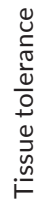




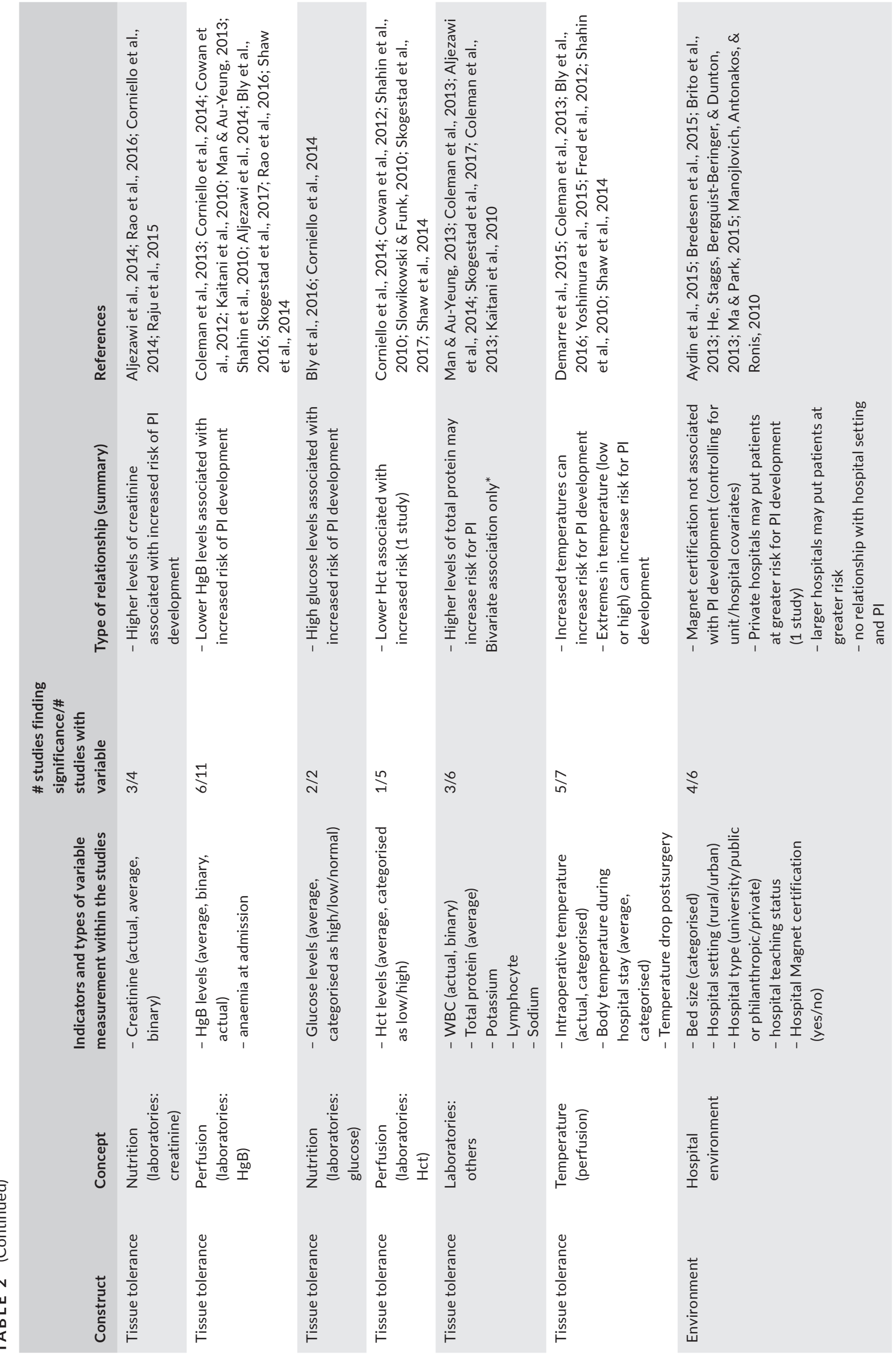




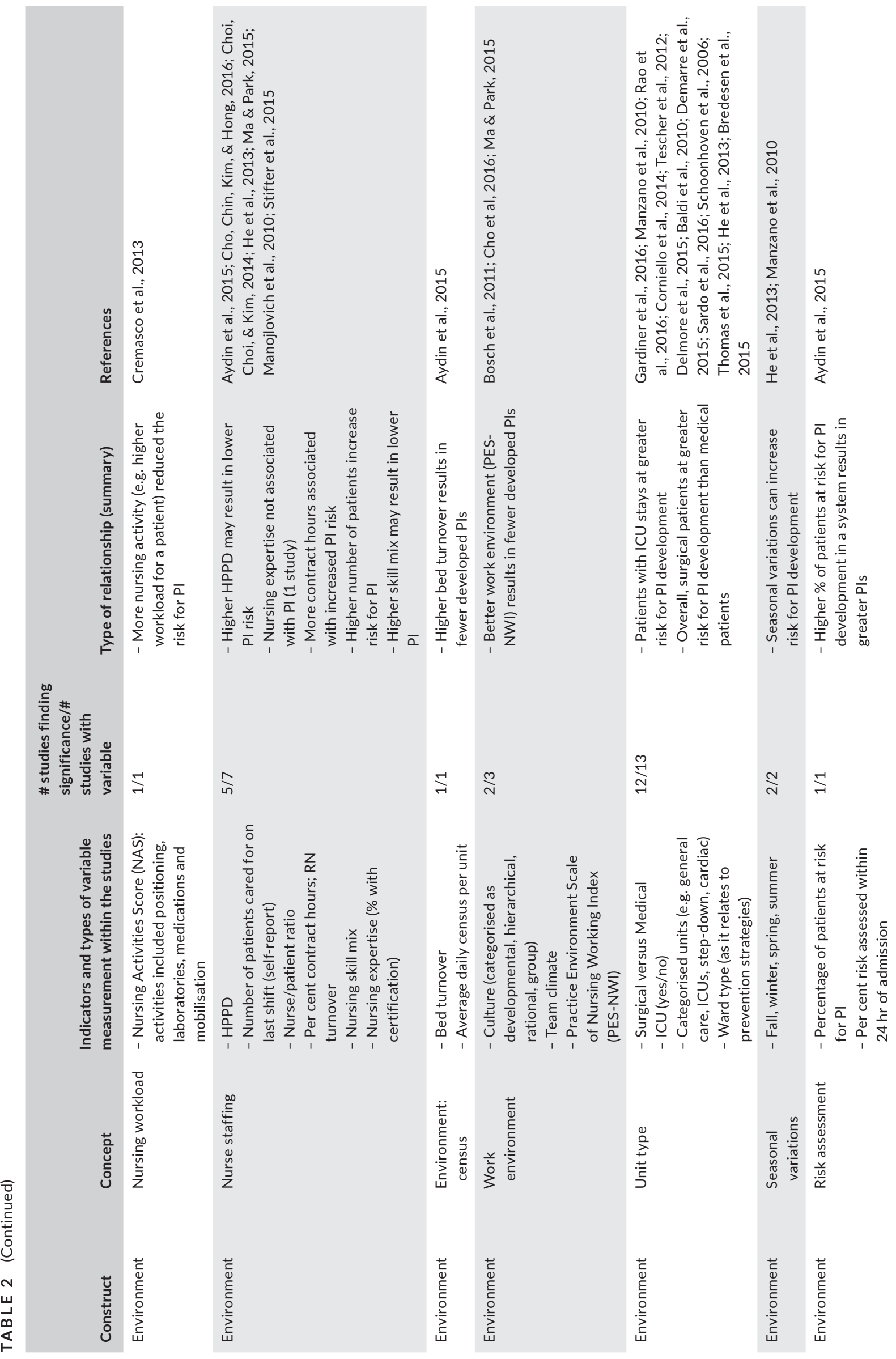




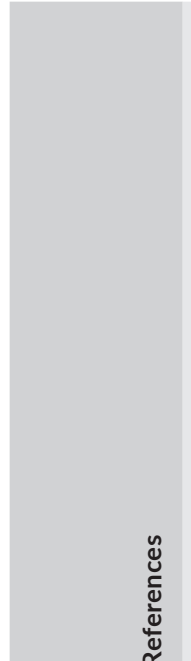

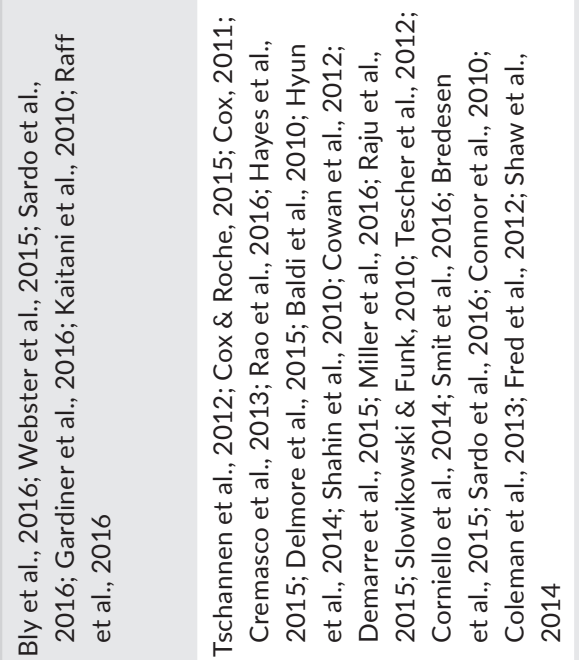

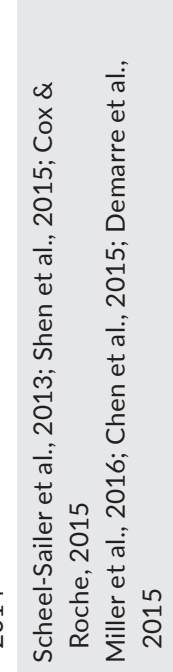

字获
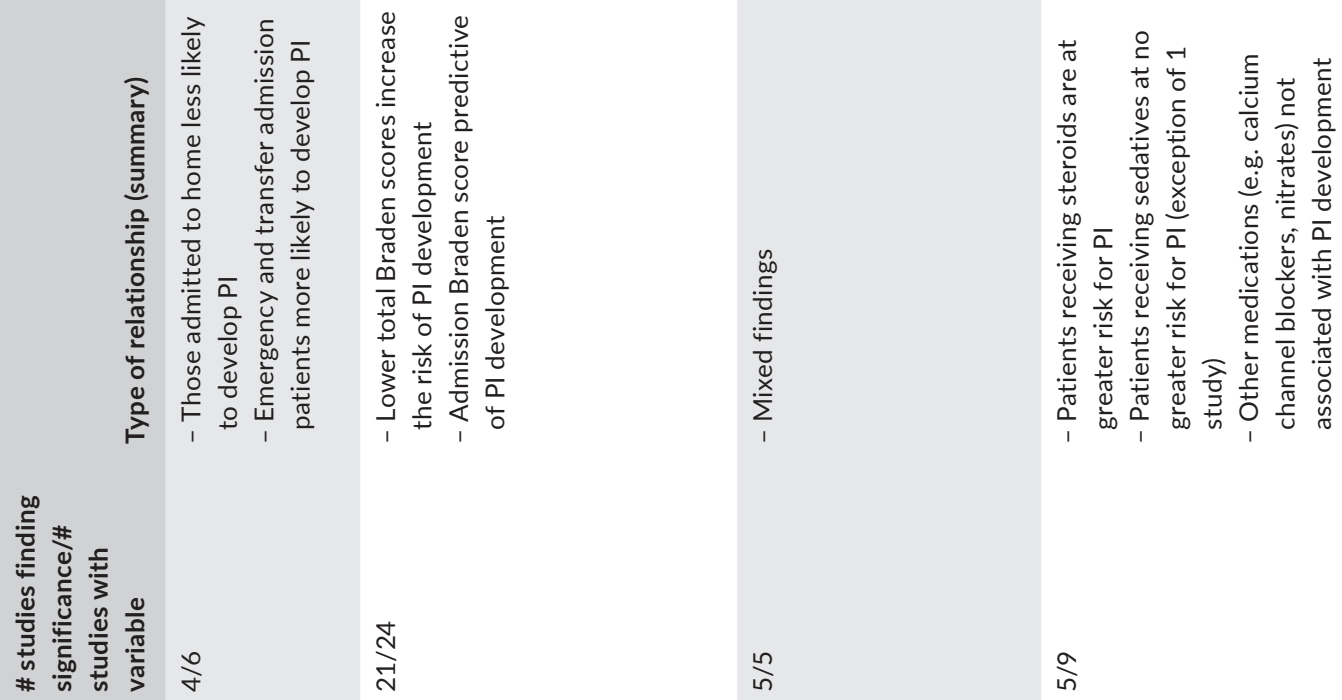

$\sum_{\substack{\pi \\ 0}}^{\infty} \frac{1}{\pi} \frac{0}{0}$

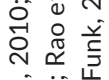

宁过岕

屯

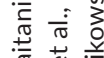

满

过卷

กั

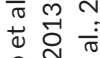

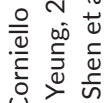
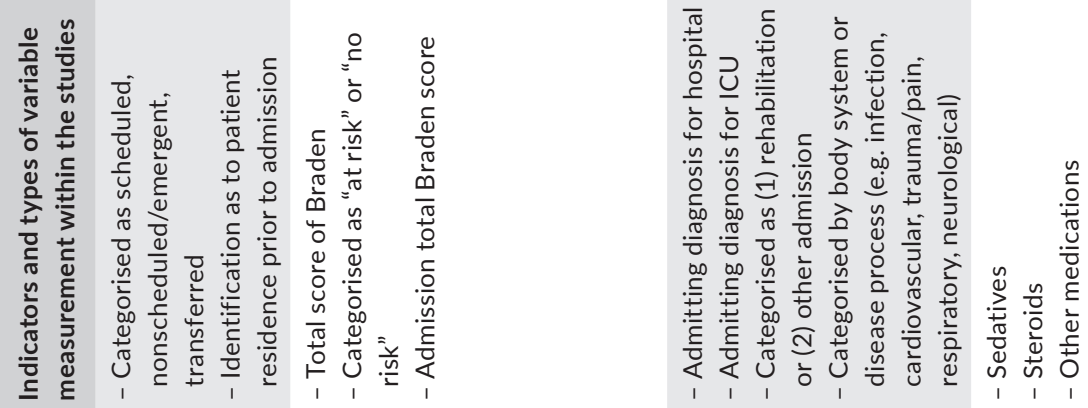

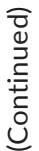
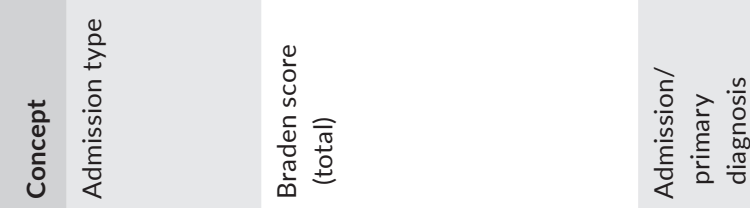

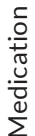

崩
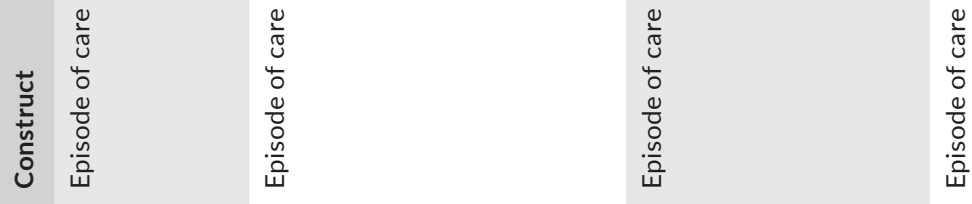


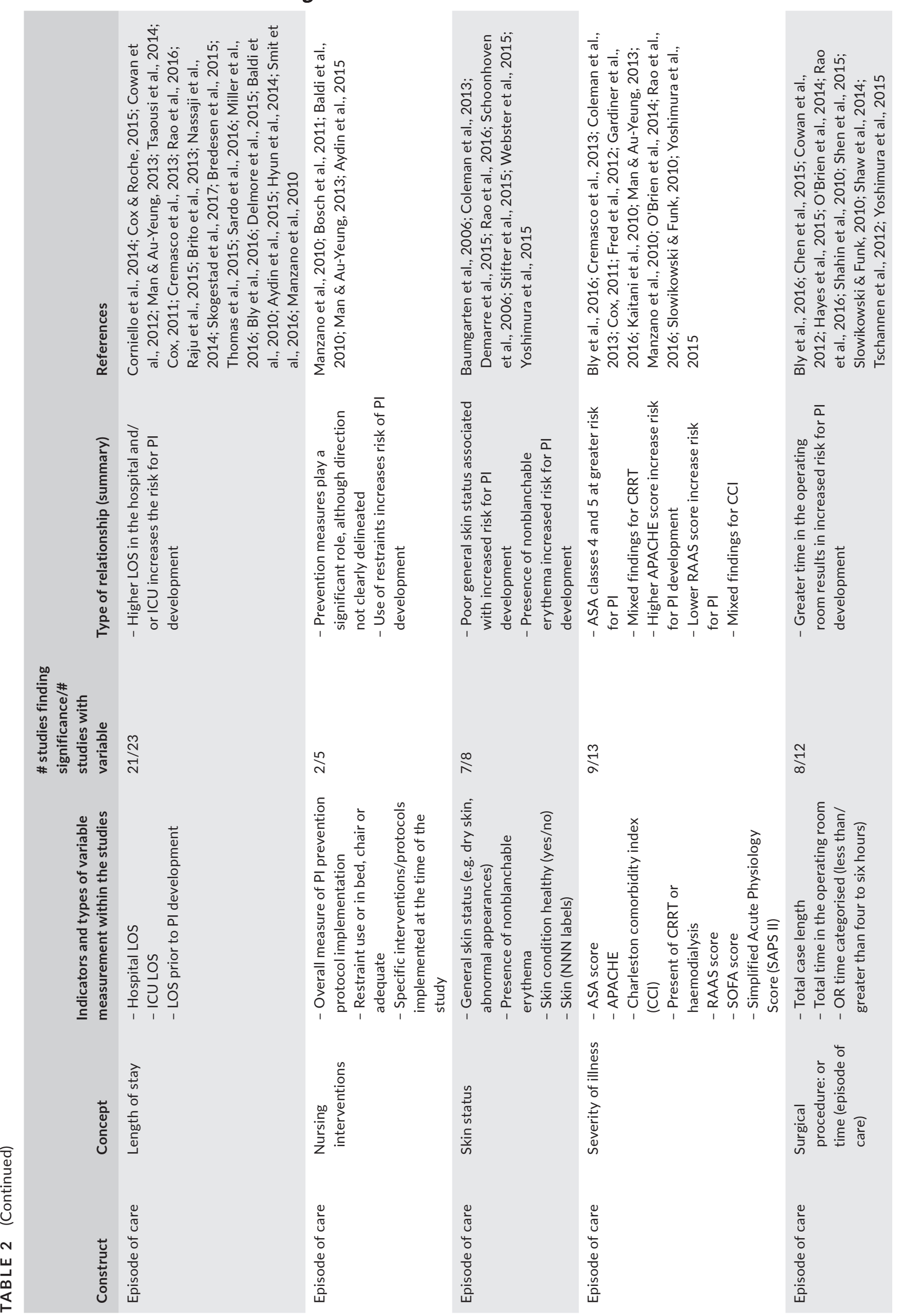




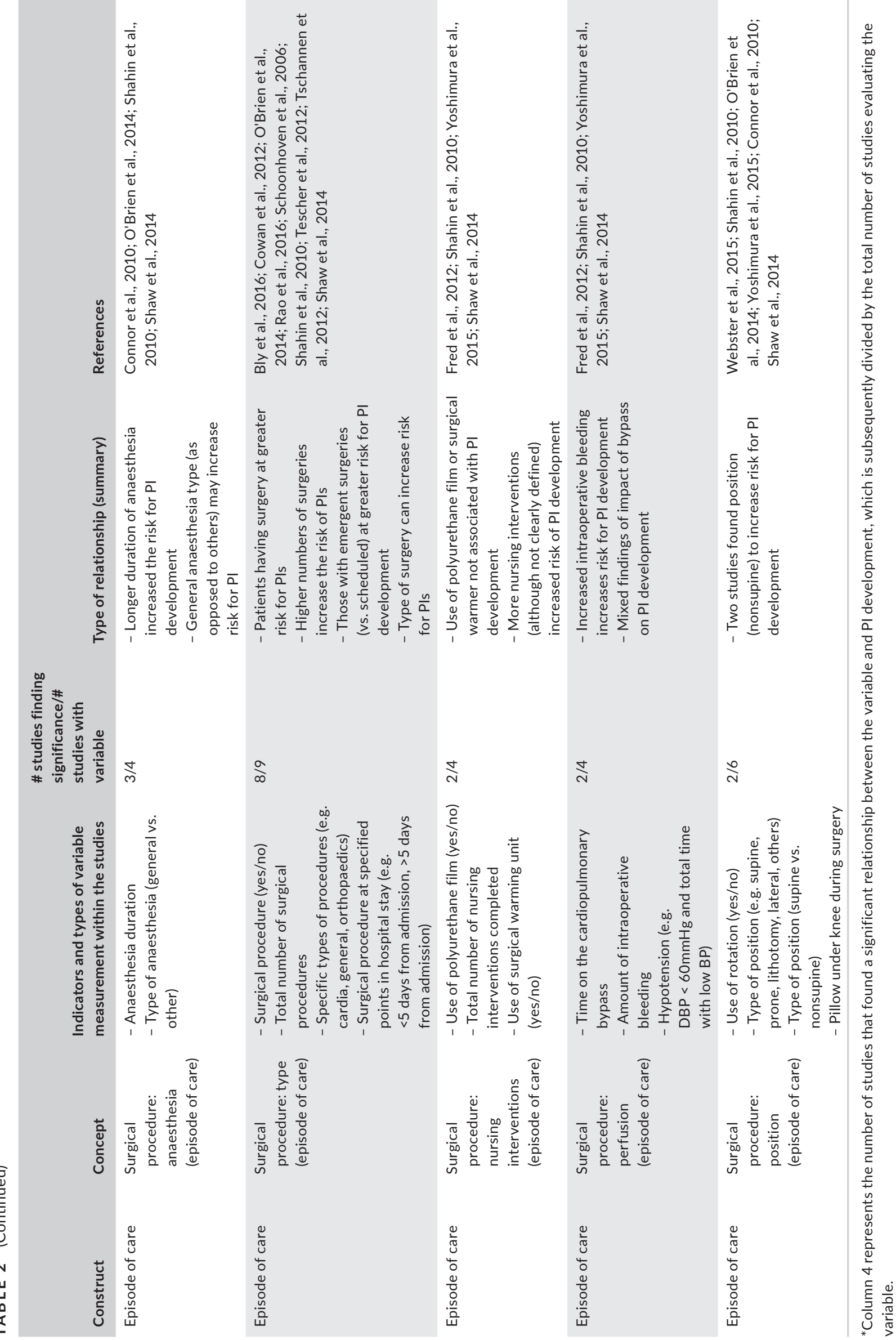


TABLE 3 Primary constructs and associated evidence evaluating prediction of concepts for hospital-acquired pressure injuries

Construct

Environment
22
Pressure

24

Tissue

41

tolerance

\# studies

49

Shear 12

tolerance

\section{References}

Aljezawi et al., 2014; Aydin et al., 2015; Baldi et al., 2010;

Baumgarten et al., 2006; Bly et al., 2016; Bredesen et al., 2015;

Brito et al., 2013; Chen et al., 2015; Coleman et al., 2013; Connor et al., 2010; Corniello et al., 2014; Cowan et al., 2012; Cox, 2011; Cox \& Roche, 2015; Cremasco et al., 2013; Delmore et al., 2015; Demarre et al., 2015; Fred et al., 2012; Gardiner et al., 2016; Hyun et al., 2014; Hayes et al., 2015; Kaitani et al., 2010; Liu et al., 2012; Man \& Au-Yeung, 2013; Manzano et al., 2010; Miller et al., 2016; Nassaji et al., 2014; O'Brien et al., 2014; Raff et al., 2016; Rao et al., 2016; Raju et al., 2015; Shen et al., 2015; Stifter et al., 2015; Sardo et al., 2016; Saunders et al., 2012; ScheelSailer et al., 2013; Schoonhoven et al., 2006; Serra et al., 2014; Shahin et al., 2010; Shaw et al., 2014; Skogestad, et al., 2017; Slowikowski \& Funk, 2010; Smit et al., 2016; Tescher et al., 2012; Thomas et al., 2015; Tsaousi et al., 2014; Tschannen et al., 2012; Webster et al., 2015; Yoshimura et al., 2015;

Aljezawi et al., 2014; Baumgarten et al., 2006; Bly et al., 2016; Brito et al., 2013; Coleman et al., 2013; Cowan et al., 2012; Cox, 2011; Delmore et al., 2015; Demarre et al., 2015; Kaitani et al., 2010; Lahmann \& Kottner, 2011; Man \& Au-Yeung, 2013; Michel et al., 2012; Raju et al., 2015; Rao et al., 2016; Schoonhoven et al., 2006; Slowikowski \& Funk, 2010; Stifter et al., 2015; Tescher et al., 2012; Webster et al., 2015; Black et al., 2010; Tsaousi et al., 2014; Yoshimura et al., 2015; Skogestad et al., 2017

Aljezawi et al., 2014; Cowan et al., 2012; Cox, 2011; Demarre et al., 2015; Kaitani et al., 2010; Lahmann \& Kottner, 2011; Raju et al., 2015; Rao et al., 2016; Schoonhoven et al., 2006; Shahin et al., 2010; Tescher et al., 2012; Shaw et al., 2014

Aljezawi et al., 2014; Beeckman et al., 2014; Brito et al., 2013; Bly et al., 2016; Banks et al., 2010; Baumgarten et al., 2006; Chen et al., 2015; Coleman et al., 2013; Connor et al., 2010; Corniello et al., 2014; Cowan et al., 2012; Cox, 2011; Cox \& Roche, 2015; Delmore et al., 2015; Demarre et al., 2015; Fred et al., 2012; Kaitani et al., 2010; Lahmann \& Kottner, 2011; Manzano et al., 2010; Michel et al., 2012; Miller et al., 2016; Man \& Au-Yeung, 2013; Nassaji et al., 2014; O'Brien et al., 2014;; Raff et al., 2016; Raju et al., 2015; Rao et al., 2016; Serra et al., 2014; Shahin et al., 2010; Stifter et al., 2015; Tescher et al., 2012; Skogestad et al., 2017; Smit et al., 2016; Shen et al., 2015; Shaw et al., 2014; Slowikowski \& Funk, 2010; Tsaousi et al., 2014; Schoonhoven et al., 2006; Tschannen et al., 2012; Webster et al., 2015; Yoshimura et al., 2015; Coleman et al, 2013

Aydin et al., 2015; Bredesen et al., 2015; Bosch et al., 2011; Brito et al., 2013; Corniello et al., 2014; Cremasco et al., 2013; Cho et al, 2016; Choi et al., 2014; Delmore et al., 2015; Baldi et al., 2010; Demarre et al., 2015; He et al., 2013; Gardiner et al., 2016; Manzano et al., 2010; Ma \& Park, 2015; Manojlovich et al., 2010; Stifter et al., 2015; Rao et al., 2016; Sardo et al., 2016; Schoonhoven et al., 2006; Tescher et al., 2012; Thomas et al., 2015 
TABLE 3 (Continued)

\begin{tabular}{|c|c|c|}
\hline Construct & \# studies & References \\
\hline $\begin{array}{l}\text { Episode of } \\
\text { care }\end{array}$ & 47 & $\begin{array}{l}\text { Aydin et al., 2015; Baldi et al., 2010; Bosch et al., 2011; } \\
\text { Baumgarten et al., 2006; Bly et al., 2016; Bredesen et al., 2015; } \\
\text { Brito et al., 2013; Chen et al., 2015; Connor et al., 2010; Coleman } \\
\text { et al., 2013; Connor et al., 2010; Corniello et al., 2014; Cox \& } \\
\text { Roche, 2015; Cox, 2011; Cremasco et al., 2013; Cowan et al., } \\
\text { 2012; Demarre et al., 2015; Delmore et al., 2015; Fred et al., } \\
\text { 2012; Gardiner et al., 2016; Hayes et al., 2015; Hyun et al., 2014; } \\
\text { Kaitani et al., 2010; Man \& Au-Yeung, 2013; Manzano et al., } \\
\text { 2010; Miller et al., 2016; Nassaji et al., 2014; O’Brien et al., 2014; } \\
\text { Raff et al., 2016; Rao et al., 2016; Shahin et al., 2010; Raju et al., } \\
\text { 2015; Sardo et al., 2016; Slowikowski \& Funk, 2010; Smit et al., } \\
\text { 2016; Shaw et al., 2014; Scheel-Sailer et al., 2013; Shen et al., } \\
\text { 2015; Schoonhoven et al., 2006; Stifter et al., 2015; Skogestad et } \\
\text { al., 2017; Thomas et al., 2015; Tescher et al., 2012; Tsaousi et al., } \\
\text { 2014; Tschannen et al., 2012; Webster et al., 2015; Yoshimura et } \\
\text { al., 2015 }\end{array}$ \\
\hline
\end{tabular}

Panel (NPUAP), shear involves two adjoining internal body parts (e.g. bone, muscle, fat) that distort in the horizontal plane of the body (NPUAP, n.d.). Measurement of shearing force and its relationship to PI development has not been fully established. Friction, which includes the rubbing of a body part with another or against another material element, is commonly included when considering the impact of shear on PI (Antokal et al., 2012). Only twelve studies considered concepts associated with friction and shear (Table 3). Despite limited measurement, studies consistently identified both friction and shear as having a significant positive relationship with risk for HAPI $(66 \%, n=8$ of 12 ) (Table 2$)$.

\subsection{4 | Other factors}

Findings from this literature review include several additional factors that were not aligned with constructs or focal concepts in the existing PI models. These factors were primarily associated with patient demographics ( $n=49$ ), environmental context ( $n=22$ studies) or episode of care ( $n=47$ studies) (Table 3). Although several patient factors were evaluated as predictors of HAPIs including ethnicity, gender, socio-economic status, height, level of consciousness and marital status, there was little support for these aspects. For example, there was only limited evidence for the predictive ability of ethnicity (38\%, $n=3$ of 8 ) and no relationship among the studies evaluating height and HAPI development ( $n=0$ of 2) (Table 2). Although marital status and socio-economic status were deemed significant predictors of HAPI development, the generalisability of these findings is limited as each factor was only evaluated in a single study, respectively (Corniello et al., 2014; Saunders, Krause, \& Acuna, 2012). Cognitive impairment, as measured by level of consciousness, presence of dementia or standardised documentation related to mental status which included various mental status scales, was believed to be a predictor in 1 of 3 studies (33\%) reviewed (Coleman et al., 2013; Cowan, Stechmiller, Rowe, \& Kairalla, 2012; Stifter et al., 2015). Although the other demographic concepts did not substantially add predictive value, studies involving environmental context and episode-of-care-related concepts show encouraging results.

Environmental context factors evaluated for HAPI risk included hospital environment, census, work environment, unit type, nurse staffing and nursing workload. Hospital environment, measured as bed size, hospital setting (rural/urban), hospital type (public/private), Magnet designation and teaching status, was typically predictive of HAPI development (66\%, $n=4$ of 6). Specific findings revealed an increased risk of HAPI development for patients admitted to larger, private hospitals. There was no relationship found between HAPI development and hospital setting or Magnet designation (e.g. recognition obtained for excellence in nursing care). Census, or bed turnover, was recognised as a significant predictor in the only study evaluating the relationship. Specifically, higher bed turnover was associated with fewer HAPIs, which may be related to patient length of stay. Work environment, measured by the unit culture or team climate, was a significant predictor in two of the three studies reviewed (66\%). Unit type was a strong predictor of HAPI ( $n=12$ of 13). Specifically, patients with an ICU stay or admitted to a surgical unit were at greater risk for HAPI. Nurse staffing, measured as hours per patient day (HPPD), skill mix and expertise, were also significant predictors of HAPI development (71\%, $n=5$ of 7$)$. Higher HPPD was negatively associated with HAPI, while higher skill mix was associated with a lower risk for HAPIs. Nursing workload was measured in one study, reporting more nursing activity resulted in a reduced risk for HAPI.

Factors directly related to the hospital episode of care where also identified in the literature review, including admission source/type, admission diagnosis, patient severity of illness, surgical experience and length of stay. Of the studies evaluating the link between admission type (e.g. scheduled, nonscheduled or transferred) and source (e.g. home, other), four $(66 \%, n=6)$ found a significant relationship. Specifically, patients admitted emergently or transferred to the hospital were at greater risk for HAPI, whereas patients who resided at home prior to admission were at 


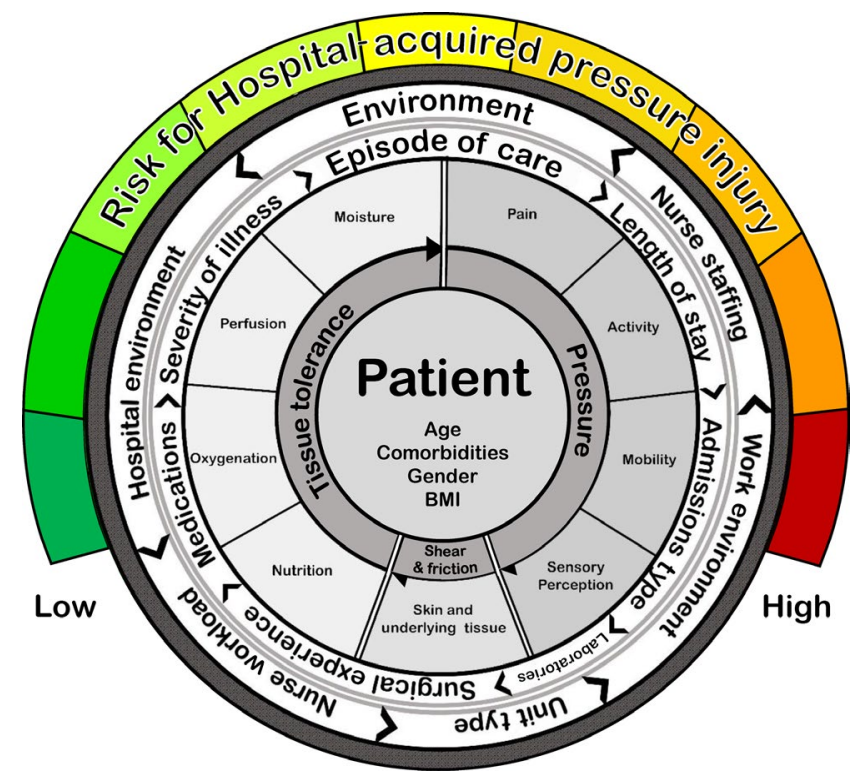

FIGURE 2 Pressure Injury Predictive Model [Colour figure can be viewed at wileyonlinelibrary.com]

lower risk for HAPI. Admission diagnosis was a significant predictor in all of the studies reviewed $(100 \%, n=5)$, but the sampling frame within each respective study limits generalisability and interpretation. Patient severity of illness, which has been measured by the American Society of Anesthesiologists (ASA) score, Acute Physiologic Assessment and Chronic Health Evaluation (APACHE), Charleston comorbidity index and Sequential Organ Failure Assessment (SOFA), was found to have a significant association with HAPI (69\%, $n=9$ of 13). Higher APACHE scores and ASA classes 4 and 5 were linked with increased risk, whereas there was a negative association between the Richmond Agitation-Sedation Scale (RAAS) scores and HAPIs. For patients undergoing surgery, factors associated with the operative experience (e.g. number or type of surgery, time on the operating table, type of anaesthesia, operative position, perfusion during the operation) potentially increased risk for HAPI development. Patients with multiple or emergent surgeries were at greater risk for HAPI ( $89 \%, n=8$ of 9 ), although the type of surgery and its relevant impact on HAPI development showed mixed results. Longer operative time resulted in an increased risk for HAPI $(66 \%, n=8$ of 12), as did patients receiving general anaesthesia or having a longer duration of anaesthesia (75\%, $n=3$ of 4). For patients with increased intraoperative bleeding or hypotensive episodes, greater risk for HAPI was shown ( $50 \%, n=2$ of 4 ). A final episode-of-care factor, patient length of stay, is still at the forefront for HAPI risk, substantiated by several reviewed studies. Length of stay, measured as total LOS and/or ICU LOS, was predictive of HAPI development in $90 \%$ of the studies reviewed ( $n=21$ of 23). Higher LOS in the hospital and/or ICU increased the risk of HAPI development. Sardo et al. (2016) found patients with a LOS greater than 20 days were at a 7.5 times greater risk for HAPI development.

\subsection{5 | Summary}

There is empirical evidence to support the inclusion of many of the focal concepts represented in the existing conceptual models used for predicting PI development. Pressure and tissue tolerance-as measured through various concepts and subconcepts-continue to be supported as predictors of PI development. Factors associated with increased pressure for longer durations of time (e.g. immobility, pain, devices) result in greater risk for PI. Factors negatively affecting tissue tolerance, including poor oxygenation, limited perfusion or excessive moisture, also contribute to PI risk. Shear, although less studied, similarly has evidence to support its relationship to PIs. There is also empirical evidence that new constructs not represented in current models are strong predictors for PI development among hospitalised patients, including additional patient demographics, environmental characteristics and episode-of-care factors. Although the discovery of this is not surprising, a model fully representing the complexity and dynamic nature of risk remains nonexistent. A complete understanding of the risk for HAPIs requires that these additional concepts be explored and integrated into PI risk models and assessments.

\section{3 | Step 3: Organising concepts and statements into an integrated and efficient representation of the phenomena of interest}

The newly developed PIPM integrates previous models for PI risk with the current evidence associated with risk for HAPI (Figure 2). During the classification phase of this step, six primary constructs emerged. Pressure, tissue tolerance and shear and friction align with earlier models. New constructs include patient, environment and episode of care. Revolving concentric circles depict the dynamic and multilevel nature of patient, episodic and environmental factors within the hospital stay that could change the level of HAPI risk for a patient. Arrows within the circles are meant to depict movement not direction, recognising the fluctuations that can occur for many of the constructs and concepts either for the better (e.g. perfusion measures are stable, adequate blood pressure) or worse (e.g. perfusion measures failing, extremely low blood pressure). Various combinations of concepts (within the constructs) can place a patient at greater or lower risk.

\subsection{1 | Pressure}

Pressure remains a primary construct in predicting risk for HAPI. The PIPM, in contrast to previous models, recognises the dynamic nature of the concepts associated with pressure, including sensory perception, activity, mobility and pain. The PIPM depicts the dynamic nature of these factors via the rotating mechanisms within the concentric circles. For example, mobility and activity levels can vary throughout a patient's hospital stay (e.g. patient fully mobile upon admission can become immobile postsurgery). Furthermore, 
interactions among the concepts may also impact risk. Patients with high levels of pain may become immobile and have reduced sensory perception, placing a patient at greater risk for HAPI development. To predict risk of HAPI, changes in these dynamic factors must be considered throughout the patient's stay.

\subsection{2 | Tissue tolerance}

The construct of tissue tolerance has been depicted in previous models identifying risk for PI development. Concepts such as perfusion, oxygenation, nutrition and moisture have significant impact on HAPI risk, as noted in the evidence. Similar to the construct of pressure, tissue tolerance is represented in the PIPM as a dynamic concept that fluctuates throughout the patient stay. Studies to date have simply looked at factors predictive of $\mathrm{PI}$ as fixed during an episode of care. Thus, patients who were mechanically ventilated for one day would have the same "risk" as a patient who had been ventilated for 21 days. Yet, the level of risk for PI may actually be exponentially higher for the patient with prolonged mechanical ventilation. The PIPM reflects this dynamically, as illustrated by the revolving arrows and the interaction effects among the various constructs and concepts. Even within the construct of tissue tolerance, interaction effects are considered, such as in the case of a patient who develops perfusion issues (e.g. haemodynamic instability) which can subsequently influence oxygenation levels. By considering variance in the concepts, a more accurate prediction of HAPI development can be determined.

\subsection{3 | Shear and friction}

Although the relationship between shear and PI development has varied among models, the limited number of studies continues to support the significant role shear plays on predicting PI. For shear to occur, friction must also be considered to accurately determine risk for HAPI; thus, both constructs are included in the PIPM. The construct of shear/ friction is impacted by pressure and tissue tolerance, as depicted in the PIPM by the revolving arrows around the concepts. Patients with skin and/or underlying tissue issues may develop a HAPI with lower levels of pressure or due to low tissue tolerance as compared to someone with healthy skin. Furthermore, interactions among the various concepts can increase risk for HAPI (e.g. underlying skin issues in addition to poor nutrition or underlying disease such as diabetes mellitus).

\subsection{4 | Patient}

Patient characteristics are relatively stable concepts that play a significant role in PI development. For this reason, the patient construct is represented as central to other risk factors for HAPI. Concepts within the patient construct, including age, gender, BMI and the presence of various comorbidities, have resulted in increased risk for HAPIs. The patient construct directly affects pressure, tissue tolerance, shear/ friction, environment and episodic factors, which subsequently affect risk for HAPI. For example, patients with a history of cardiac disease already have impaired perfusion, which can become exacerbated during hospitalisation, especially if undergoing surgery, for example.

\subsection{5 | Episode of care}

A significant enhancement to previous PI models accounts for the complex nature of care processes and patient response to care during a hospitalisation. The episode-of-care concentric circle depicts the factors within a hospitalisation that can drastically modify risk for HAPI. Episodic factors include both fixed (e.g. admission type) and dynamic factors (e.g. surgical experiences, patient illness severity, medications, length of stay) associated with the stay. As patients undergo a surgical procedure, for example, changes in many of the concepts-at least for a time-may be evident, including reduced mobility/activity due to anaesthesia and procedure time, poor nutrition due to NPO status, or pain associated with the surgical procedure. These changes can result in increased risk for HAPI and thus may require further nursing interventions aimed at prevention.

\subsection{6 | Environment}

A further enhancement from current models is the inclusion of environment. Empirical evidence strongly supports the impact of nursing workload, unit type, nurse staffing levels and hospital environment on the development of HAPIs. The new model recognises the complexity associated with care delivery in the hospital setting, such that changes in the environmental characteristics can impact PI development. Changes in some of the concepts-nurse staffing, unit type and workload-can occur frequently throughout a patient stay. According to the PIPM, these factors must be evaluated throughout the hospital stay to determine their impact on HAPI development.

In summary, the PIPM represents the dynamic nature of PI risk for a hospitalised patient. A multitude of combinations of the constructs and concepts throughout the model can drastically increase or decrease risk to a hospitalised patient. This is the first PI risk model to represent the environment and episode-of-care factors associated with HAPI development. Inadequate staffing levels or high workload (environment) combined with an immobile patient (pressure) with poor nutrition (tissue tolerance) recovering from a 10-hr surgery (episode of care) would be at significant risk for HAPI. When the interaction effects of the various combinations of concepts are considered as denoted in the PIPM, those at risk for HAPI can more accurately be determined.

\section{RELEVANCE TO CLINICAL PRACTICE}

Studies have identified interventions to reduce PI risk and evidencebased treatment plans for those who develop PIs (Berlowitz et al., 
2011; Institute for Healthcare Improvement, 2011). Accurate risk identification is the first step in prevention. Current models fail to consider the magnitude of factors predictive of PIs that have been empirically identified over the past several years. Thus, allocation of evidence-based PI prevention care to the right person at the right time remains elusive. This discursive paper reports on the use of Walker and Avant's (2005) theory synthesis model to examine the accuracy of PI frameworks-as it aligns with the evidence-in predicting risk for hospital-acquired PIs. Through a synthesis of current conceptual frameworks and relevant literature, a new model for PI risk emerged.

The PIPM is the first conceptual model representing the complexity and dynamic nature of HAPI risk for hospitalised patients, thus improving the accuracy of HAPI risk identification. Recognition of environment and episode-of-care-related factors affecting HAPI risk, in addition to the consideration for continuous variation in other factors, significantly improves upon current models. Although some environmental and episodic factors cannot be modified, recognition of the role these factors play in risk is important. For example, organisational leadership may want to consider specialty beds for all ICU patients or those of elder years with multiple comorbidities.

Optimisation of prevention among hospitalised patients requires early identification of risk that is accurate and precise, followed by aggressive preventive interventions. The PIPM reflects the synthesis of conceptual frameworks with current evidence, resulting in an all-encompassing depiction of PI risk. Use of the model may assist in a more accurate identification of risk among hospitalised patients. Rather than relying on a risk assessment completed once a shift, data from the medical record can be reviewed more consistently (e.g. every 2-4 hr), identifying combinations of factors that may put a patient at risk. For example, the combination of factors for Patient A may include patient (diabetic, older people, history of hypertension), tissue tolerance (mechanically ventilated, hypotensive), episode-of-care (undergoing extensive surgical procedure, currently receiving vasopressors) and environmental factors (admitted to the ICU) that signify high levels of risk for PI. Another example may be a patient with obesity and diabetes (patient factors), mobility limitations (pressure factors) and the need for supplemental oxygen (tissue tolerance factors), who was an emergent admission resulting in a long length of stay (episode-of-care factors) where low staffing (environment) was identified. Clinicians could use such information to guide their decision-making related to priority interventions.

Understanding the various combinations of factors can aid in the development of risk profiles which can then be aligned with individual intervention. For example, a patient with a risk profile including multiple chronic conditions (e.g. diabetes mellitus, cardiovascular disease) with a recent hypotensive event scheduled for an extensive surgery may need alternative support surfaces or pressure redistribution overlays (higher cost) or more frequent pressure relief during a surgical procedure (AORN Guidelines for Perioperative Practice, 2019), whereas a patient risk profile including normal BMI, haemodynamically sound vitals and no underlying conditions undergoing the same procedure may only require the standard intraoperative mattress (lower cost) and repositioning protocol. More strategic deployment of critical resources and implementation of nursing interventions tailored to the risk profile may result not only in a reduction of HAPIs, but also improved cost efficiencies.

The new conceptual framework also has implications for future research. For example, empirical testing to assure relationships between the various concepts are adequately represented in the model is required. Interaction effects among the various concepts must be evaluated, which may result in the development of a more accurate, robust model of risk factors, including recognition of variables most predictive of PIs. The analysis of large-scale data sets from electronic health records is one method of achieving this aim. The PIPM is a first step towards representing pressure injury dynamics. Extending the model using complex system methods such as agent-based modelling may further our understanding of the mechanisms involved in the development of pressure injuries over time, leading to improved understanding of risk and subsequent clinical care for hospitalised patients.

\section{ACKNOWLEDGEMENTS}

We wish to express our gratitude to Shannon Coon for her significant contribution in editing and formatting the model.

\section{CONFLICT OF INTEREST}

The authors have no conflicts of interest to report.

\section{ORCID}

Dana Tschannen iD https://orcid.org/0000-0001-5553-2109

\section{REFERENCES}

AHRQ. (2018). AHRQ National Scorecard on Hospital-Acquired Conditions: Updated Baseline Rates and Preliminary Results 2014-2016. Rockville, MD: Agency for Healthcare Research and Quality. Retrieved from https://www.ahrq.gov/professionals/quality-patient-safety/pfp/ index.html

Aljezawi, M., Al Qadire, M., \& Tubaishat, A. (2014). Pressure ulcers in long-term care: A point prevalence study in Jordan. British Journal of Nursing, 23(Suppl 6), S4, S6, S8, S10-11. https://doi.org/10.12968/ bjon.2014.23.Sup6.S4

Antokal, S., Brienza, D., Bryan, N., Herbe, L., Logan, S., Maguire, J., ... Siddiqui, A. (2012). Friction induced skin injuries - Are they pressure ulcers?. A National Pressure Ulcer Advisory Panel white paper. Retrieved from https://www.npuap.org/wp-content/uploads/2012/01/ NPUAP-Friction-White-Paper.pdf

AORN Guidelines for Perioperative Practice (2019). Denver, CO, USA: AORN (Association of periOperative Registered Nurses). Retrieved from http://online.statref.com.proxy.lib.umich.edu/Document.aspx?docAddress=mPG6UpteT2QwmCP-hGCaOw!!\&Sessionld=2BB7A 6DWJJ OSPNXM\#H\&7\&ChaptersTab\&BT_I3hjT3A4vogelFL $3 \mathrm{hRQ} ! ! \& \& 234$

Aydin, C., Donaldson, N., Stotts, N. A., Fridman, M., \& Brown, D. S. (2015). Modeling hospital-acquired pressure ulcer prevalence on medical-surgical units: Nurse workload, expertise, and clinical processes of care. Health Services Research, 50(2), 351-373. https://doi. org/10.1111/1475-6773.12244 
Baldi, I., Ferrando, A., Foltran, F., Ciccone, G., \& Gregori, D. (2010). Studying factors related to pressure ulcers prevention: A marginal scale model for modelling heterogeneity among hospitals. Journal of Evaluation in Clinical Practice, 16(6), 1085-1089. https://doi. org/10.1111/j.1365-2753.2009.01257.x

Banks, M. D., Graves, N., Bauer, J. D., \& Ash, S. (2010). The costs arising from pressure ulcers attributable to malnutrition. Clinical Nutrition, 29(2), 180-186. https://doi.org/10.1016/j.clnu.2009.08.006

Baumgarten, M., Margolis, D. J., Localio, A. R., Kagan, S. H., Lowe, R. A., Kinosian, B., ... Ruffin, A. (2006). Pressure ulcers among elderly patients early in the hospital stay. Journals of Gerontology Series A-Biological Sciences \& Medical Sciences, 61(7), 749-754. https://doi. org/10.1093/gerona/61.7.749

Beeckman, D., Van Lancker, A., Van Hecke, A., \& Verhaeghe, S. (2014). A systematic review and meta-analysis of incontinence-associated dermatitis, incontinence, and moisture as risk factors for pressure ulcer development. Research in Nursing \& Health, 37(3), 204-218. https:// doi.org/10.1002/nur.21593

Benoit, R., \& Mion, L. (2012). Risk factors for pressure ulcer development in critically III patients: A conceptual model to guide research. Research in Nursing \& Health, 35(4), 340-362. https://doi. org/10.1002/nur.21481

Berlowitz, D., VanDeusen Lukas, C., Parker, V., Niederhauser, A., Silver, J., Logan, C., \& Ayello, E. (2011). Preventing pressure ulcers in hospitals: A toolkit for improving quality of care. Rockville, MD: Agency for Healthcare Research and Quality. Retrieved from https://www.ahrq. gov/professionals/systems/hospital/pressureulcertoolkit/index. html

Black, J., Baharestani, M., Black, S., Cavazos, J., Conner-Kerr, T., Edsberg, L., ... Schultz, G. (2010). An overview of tissue types in pressure ulcers: A consensus panel recommendation. Ostomy Wound Management, 56(4), 28-44.

Bly, D., Schallom, M., Sona, C., \& Klinkenberg, D. (2016). A model of pressure, oxygenation, and perfusion risk factors for pressure ulcers in the intensive care unit. American Journal of Critical Care, 25(2), 156164. https://doi.org/10.4037/ajcc2016840

Bosch, M., Halfens, R. J., van der Weijden, T., Wensing, M., Akkermans, R., \& Grol, R. (2011). Organizational culture, team climate, and quality management in an important patient safety issue: Nosocomial pressure ulcers. Worldviews on Evidence-Based Nursing, 8(1), 4-14. https:// doi.org/10.1111/j.1741-6787.2010.00187.x

Braden, B., \& Bergstrom, N. (1987). A conceptual schema for the study of the etiology of pressure sores. Rehabilitation Nursing, 12(1), 8-16. https://doi.org/10.1002/j.2048-7940.1987.tb00541.x

Bredesen, I. M., Bjoro, K., Gunningberg, L., \& Hofoss, D. (2015). Patient and organisational variables associated with pressure ulcer prevalence in hospital settings: A multilevel analysis. British Medical Journal Open, 5(8), e007584. https://doi.org/10.1136/bmjop en-2015-007584

Brito, P. A., de Vasconcelos Generoso, S., \& Correia, M. I. (2013). Prevalence of pressure ulcers in hospitals in Brazil and association with nutritional status-A multicenter, cross-sectional study. Nutrition, 29(4), 646-649. https://doi.org/10.1016/j. nut.2012.11.008

Chen, H., Shen, W., Xu, Y., Zhang, Q., \& Wu, J. (2015). Perioperative corticosteroids administration as a risk factor for pressure ulcers in cardiovascular surgical patients: A retrospective study. International Wound Journal, 12(5), 581-585. https://doi.org/10.1111/iwj.12168

Choi, J., Choi, J., \& Kim, H. (2014). Nurses' interpretation of patient status descriptions on the Braden Scale. Clinical Nursing Research, 23(3), 336-346. https://doi.org/10.1177/1054773813486477

Cho, E., Chin, D., Kim, S. \& Hong, O. (2016). The relationship of nurse staffing level and work environment with patient adverse events. Journal of Nursing Scholarship, 48(1), 74-82. https://doi.org/10.1177/10547 73813486477
Coleman, S., Gorecki, C., Nelson, E. A., Closs, S. J., Defloor, T., Halfens, R., ... Nixon, J. (2013). Patient risk factors for pressure ulcer development: Systematic review. International Journal of Nursing Studies, 50(7), 974-1003. https://doi.org/10.1016/j.ijnurstu.2012.11.019

Coleman, S., Nixon, J., Keen, J., Wilson, L., McGinnis, E., Dealey, C., ... Nelson, E. A. (2014). A new pressure ulcer conceptual framework. Journal of Advanced Nursing, 70(10), 2222-2234. https://doi. org/10.1111/jan.12405

Connor, T., Sledge, J. A., Bryant-Wiersema, L., Stamm, L., \& Potter, P. (2010). Identification of pre-operative and intra-operative variables predictive of pressure ulcer development in patients undergoing urologic surgical procedures. Urologic Nursing, 30(5), 289-295, 305. https://doi.org/10.7257/1053-816X.2010.30.5.289

Corniello, A. L., Moyse, T., Bates, J., Karafa, M., Hollis, C., \& Albert, N. M. (2014). Predictors of pressure ulcer development in patients with vascular disease. Journal of Vascular Nursing, 32(2), 55-62. https:// doi.org/10.1016/j.jvn.2013.07.002

Cowan, L. J., Stechmiller, J. K., Rowe, M., \& Kairalla, J. A. (2012). Enhancing Braden pressure ulcer risk assessment in acutely ill adult veterans. Wound Repair \& Regeneration, 20(2), 137-148. https://doi. org/10.1111/j.1524-475X.2011.00761.x

Cox, J. (2011). Predictors of pressure ulcers in adult critical care patients. American Journal of Critical Care, 20(5), 364-375. https://doi. org/10.4037/ajcc2011934

Cox, J., \& Roche, S. (2015). Vasopressors and development of pressure ulcers in adult critical care patients. American Journal of Critical Care, 24(6), 501-510. https://doi.org/10.4037/ajcc2015123

Cremasco, M. F., Wenzel, F., Zanei, S. S., \& Whitaker, I. Y. (2013). Pressure ulcers in the intensive care unit: The relationship between nursing workload, illness severity and pressure ulcer risk. Journal of Clinical Nursing, 22(15-16), 2183-2191. https://doi. org/10.1111/j.1365-2702.2012.04216.x

Defloor, T. (1999). The risk of pressure sores: A conceptual scheme. Journal of Clinical Nursing, 8(2), 206-216. https://doi. org/10.1046/j.1365-2702.1999.00254.x

Delmore, B., Lebovits, S., Suggs, B., Rolnitzky, L., \& Ayello, E. A. (2015). Risk factors associated with heel pressure ulcers in hospitalized patients. Journal of Wound, Ostomy and Continence Nursing, 42(3), 242248; quiz E241-242. https://doi.org/10.1097/WON.0000000000 000134

Demarre, L., Verhaeghe, S., Van Hecke, A., Clays, E., Grypdonck, M., \& Beeckman, D. (2015). Factors predicting the development of pressure ulcers in an at-risk population who receive standardized preventive care: Secondary analyses of a multicentre randomised controlled trial. Journal of Advanced Nursing, 71(2), 391-403. https://doi. org/10.1111/jan.12497

Fred, C., Ford, S., Wagner, D., \& VanBrackle, L. (2012). Intraoperatively acquired pressure ulcers and perioperative normothermia: A look at relationships [Erratum appears in AORN J. 2012 Nov;96(5):527]. AORN Journal, 96(3), 251-260. https://doi.org/10.1016/j.aorn.2012.06.014

García-Fernández, F. P., Agreda, J. J. S., Verdú, J., \& Pancorbo-Hidalgo, P. L. (2014). A new theoretical model for the development of pressure ulcers and other dependence-related lesions. Journal of Nursing Scholarship, 46(1), 28-38. https://doi.org/10.1111/jnu.12051

Gardiner, J. C., Reed, P. L., Bonner, J. D., Haggerty, D. K., \& Hale, D. G. (2016). Incidence of hospital-acquired pressure ulcers-A population-based cohort study. International Wound Journal, 13(5), 809820. https://doi.org/10.1111/iwj.12386

Hayes, R. M., Spear, M. E., Lee, S. I., Krauser Lupear, B. E., Benoit, R. A., Valerio, R., \& Dmochowski, R. R. (2015). Relationship between time in the operating room and incident pressure ulcers: A matched casecontrol study. American Journal of Medical Quality, 30(6), 591-597. https://doi.org/10.1177/1062860614545125

He, J., Staggs, V. S., Bergquist-Beringer, S., \& Dunton, N. (2013). Unit-level time trends and seasonality in the rate of hospital-acquired pressure 
ulcers in US acute care hospitals. Research in Nursing \& Health, 36(2), 171-180. https://doi.org/10.1002/nur.21527

Hyun, S., Li, X., Vermillion, B., Newton, C., Fall, M., Kaewprag, P., ... Lenz, E. R. (2014). Body mass index and pressure ulcers: Improved predictability of pressure ulcers in intensive care patients. American Journal of Critical Care, 23(6), 494-501. https://doi.org/10.4037/ ajcc2014535

Institute for Healthcare Improvement (2011). How-to Guide: Prevent Pressure Ulcers. Cambridge, MA: Institute for Healthcare Improvement. Retrieved from http://www.ihi.org/resources/Pages/ Tools/HowtoGuidePreventPressureUlcers.aspx

Kaitani, T., Tokunaga, K., Matsui, N., \& Sanada, H. (2010). Risk factors related to the development of pressure ulcers in the critical care setting. Journal of Clinical Nursing, 19(3-4), 414-421. https://doi. org/10.1111/j.1365-2702.2009.03047.x

Kosiak, M., Kubicek, W. G., Olson, M., Danz, J. N., \& Kottke, F. J. (1958). Evaluation of pressure as a factor in the production of ischial ulcers. Archives of Physical Medicine \& Rehabilitation, 39(10), 623-629.

Lahmann, N. A., \& Kottner, J. (2011). Relation between pressure, friction and pressure ulcer categories: A secondary data analysis of hospital patients using CHAID methods. International Journal of Nursing Studies, 48(12), 1487-1494. https://doi.org/10.1016/j.ijnur stu.2011.07.004

Liu, P., He, W., \& Chen, H. L. (2012). Diabetes mellitus as a risk factor for surgery-related pressure ulcers: A meta-analysis. Journal of Wound, Ostomy, \& Continence Nursing, 39(5), 495-499. https://doi. org/10.1097/WON.0b013e318265222a

Lyder, C. H., Wang, Y., Metersky, M., Curry, M., Kliman, R., Verzier, N. R., \& Hunt, D. R. (2012). Hospital-acquired pressure ulcers: Results from the national medicare patient safety monitoring system study. Journal of the American Geriatrics Society, 60(9), 1603-1608. https:// doi.org/10.1111/j.1532-5415.2012.04106.x

Ma, C., \& Park, S. H. (2015). Hospital magnet status, unit work environment, and pressure ulcers. Journal of Nursing Scholarship, 47(6), 565573. https://doi.org/10.1111/jnu.12173

Man, S. P., \& Au-Yeung, T. W. (2013). Hypotension is a risk factor for new pressure ulcer occurrence in older patients after admission to an acute hospital. Journal of the American Medical Directors Association, 14(8), 627.e1-627.e5. https://doi.org/10.1016/j. jamda.2013.05.003

Manojlovich, M., Antonakos, C. L., \& Ronis, D. L. (2010). The relationship between hospital size and ICU type on select adverse patient outcomes. Hospital Topics, 88(2), 33-42. https://doi.org/10.1080/00185 861003768845

Manzano, F., Navarro, M. J., Roldán, D., Moral, M. A., Leyva, I., Guerrero, C., ... Fernández-Mondejar, E. (2010). Pressure ulcer incidence and risk factors in ventilated intensive care patients. Journal of Critical Care, 25(3), 469-476. https://doi.org/10.1016/j.jcrc.2009.09.002

Melnyk, B. M., \& Fineout-Overholt, E. (2011). Evidence-based practice in nursing \& healthcare : A guide to best practice (2nd ed.). Philadelphia, PA: Lippincott Williams \& Wilkins.

Michel, J. M., Willebois, S., Ribinik, P., Barrois, B., Colin, D., \& Passadori, Y. (2012). As of 2012, what are the key predictive risk factors for pressure ulcers? Developing French guidelines for clinical practice. Annals of Physical and Rehabilitation Medicine, 55(7), 454-465. https ://doi.org/10.1016/j.rehab.2012.08.003

Miller, N., Frankenfield, D., Lehman, E., Maguire, M., \& Schirm, V. (2016). Predicting pressure ulcer development in clinical practice: Evaluation of Braden scale scores and nutrition parameters. Journal of Wound, Ostomy \& Continence Nursing, 43(2), 133-139. https://doi. org/10.1097/WON.0000000000000184

Nassaji, M., Askari, Z., \& Ghorbani, R. (2014). Cigarette smoking and risk of pressure ulcer in adult intensive care unit patients. International Journal of Nursing Practice, 20(4), 418-423. https://doi.org/10.1111/ ijn.12141
National Pressure Ulcer Advisory Panel (2016). NPUAP pressure injury stages. Retrieved from http://www.npuap.org/resources/educational-and-clinical-resources/npuap-pressure-injury-stages/

Nightingale, F. (1859). Notes on nursing. London: Harrison, 59, Pall Mall.

NPUAP. (n.d.). Shear: A contributory factor in pressure ulceration. Retrieved from http://www.npuap.org/resources/educational-andclinical-resources/shear-force-slide-set/

O'Brien, D. D., Shanks, A. M., Talsma, A., Brenner, P. S., \& Ramachandran, S. K. (2014). Intraoperative risk factors associated with postoperative pressure ulcers in critically ill patients: A retrospective observational study. Critical Care Medicine, 42(1), 40-47. https://doi.org/10.1097/ CCM.0b013e318298a849

Raff, L. A., Waller, H., Griffin, R. L., Kerby, J. D., \& Bosarge, P. L. (2016). Identification of risk factors for the development of pressure ulcers despite standard screening methodology and prophylaxis in trauma patients. Advances in Skin \& Wound Care, 29(7), 329-334. https://doi. org/10.1097/01.ASW.0000484064.86180.18

Raju, D., Su, X., Patrician, P. A., Loan, L. A., \& McCarthy, M. S. (2015). Exploring factors associated with pressure ulcers: A data mining approach. International Journal of Nursing Studies, 52(1), 102-111. https ://doi.org/10.1016/j.ijnurstu.2014.08.002

Rao, A. D., Preston, A. M., Strauss, R., Stamm, R., \& Zalman, D. C. (2016). Risk factors associated with pressure ulcer formation in critically ill cardiac surgery patients: A systematic review. Journal of Wound, Ostomy \& Continence Nursing, 43(3), 242-247. https://doi. org/10.1097/WON.0000000000000224

Russo, C. A., Steiner, C., \& Spector, W. (2006). Hospitalizations related to pressure ulcers among adults 18 years and older, 2006: Statistical Brief \#64 Healthcare Cost and Utilization Project (HCUP) Statistical Briefs. Rockville, MD: Agency for Health Care Policy and. Research (US).

Sardo, P. M. G., Simões, C. S. O., Alvarelhão, J. J. M., Simões, J. F. F. L., Machado, P. A. P., Amado, F. M. L., ... Melo, E. M. O. P. D. (2016), Analyses of pressure ulcer incidence in inpatient setting in a Portuguese hospital. Journal of Tissue Viability, 25(4), 209-215. https ://doi.org/10.1016/j.jtv.2016.08.003

Saunders, L. L., Krause, J. S., \& Acuna, J. (2012). Association of race, socioeconomic status, and health care access with pressure ulcers after spinal cord injury. Archives of Physical Medicine and Rehabilitation, 93(6), 972-977. https://doi.org/10.1016/j.apmr.2012.02.004

Scheel-Sailer, A., Wyss, A., Boldt, C., Post, M. W., \& Lay, V. (2013). Prevalence, location, grade of pressure ulcers and association with specific patient characteristics in adult spinal cord injury patients during the hospital stay: A prospective cohort study. Spinal Cord, 51(11), 828-833. https://doi.org/10.1038/sc.2013.91

Schoonhoven, L., Grobbee, D. E., Donders, A. R., Algra, A., Grypdonck, M. H., Bousema, M. T., ... prePURSE Study Group. (2006). Prediction of pressure ulcer development in hospitalized patients: A tool for risk assessment. Quality \& Safety in Health Care, 15(1), 65-70. https://doi. org/10.1136/qshc.2005.015362

Serra, R., Caroleo, S., Buffone, G., Lugarà, M., Molinari, V., Tropea, F., ... de Franciscis, S. (2014). Low serum albumin level as an independent risk factor for the onset of pressure ulcers in intensive care unit patients. International Wound Journal, 11(5), 550-553. https://doi. org/10.1111/iwj.12004

Shahin, E. S., Meijers, J. M., Schols, J. M., Tannen, A., Halfens, R. J., \& Dassen, T. (2010). The relationship between malnutrition parameters and pressure ulcers in hospitals and nursing homes. Nutrition, 26(9), 886-889. https://doi.org/10.1016/j.nut.2010.01.016

Shaw, L. F., Chang, P. C., Lee, J. F., Kung, H. Y., \& Tung, T. H. (2014). Incidence and predicted risk factors of pressure ulcers in surgical patients: Experience at a medical center in Taipei, Taiwan. BioMed Research International, 2014, 416896. https://doi.org/10.1155/2014/416896

Shen, W. M. N., Chen, H. M. N., Xu, Y. M. N., Zhang, Q. M. N., \& Wu, J. M. N. (2015). The relationship between length of surgery and the incidence of pressure ulcers in cardiovascular surgical patients: A 
retrospective study. Advances in Skin \& Wound Care, 28(10), 444450. https://doi.org/10.1097/01.ASW.0000466365.90534.b0

Skogestad, I. J., Martinsen, L., Børsting, T. E., Granheim, T. I., Ludvigsen, E. S., Gay, C. L., \& Lerdal, A. (2017). Supplementing the Braden scale for pressure ulcer risk among medical inpatients: The contribution of self-reported symptoms and standard laboratory tests. Journal of Clinical Nursing, 26(1-2), 202-214. https://doi.org/10.1111/ jocn.13438 (Published online ahead of print June 20, 2016)

Slowikowski, G. C., \& Funk, M. (2010). Factors associated with pressure ulcers in patients in a surgical intensive care unit. Journal of Wound, Ostomy, \& Continence Nursing, 37(6), 619-626. https://doi. org/10.1097/WON.0b013e3181f90a34

Smit, I., Harrison, L., Letzkus, L., \& Quatrara, B. (2016). What factors are associated with the development of pressure ulcers in a medical intensive care unit? Dimensions of Critical Care Nursing, 35(1), 37-41. https://doi.org/10.1097/DCC.0000000000000153

Spector, W., Limcangco, R., Owens, P., \& Steiner, C. (2016). Marginal hospital cost of surgery-related hospital-acquired pressure ulcers. Medical Care, 54(9), 845-851. https://doi.org/10.1097/MLR.00000 00000000558

Stifter, J., Yao, Y., Lodhi, M. K., Lopez, K. D., Khokhar, A., Wilkie, D. J., \& Keenan, G. M. (2015). Nurse continuity and hospital-acquired pressure ulcers: A comparative analysis using an electronic health record "Big Data" set. Nursing Research, 64(5), 361-371. https://doi. org/10.1097/NNR.0000000000000112

Tescher, A. N., Branda, M. E., Byrne, T. J., \& Naessens, J. M. (2012). All at-risk patients are not created equal: Analysis of Braden pressure ulcer risk scores to identify specific risks. Journal of Wound, Ostomy, \& Continence Nursing, 39(3), 282-291. https://doi.org/10.1097/ WON.0b013e3182435715

Thomas, D. R., Goode, P. S., Tarquine, P. H., \& Allman, R. M. (1996). Hospital-acquired pressure ulcers and risk of death. Journal of the American Geriatrics Society, 44(12), 1435-1440. https://doi. org/10.1111/j.1532-5415.1996.tb04067.x
Thomas, E., Vinodkumar, S., Mathew, S., \& Setia, M. (2015). A study of the factors associated with risk for development of pressure ulcers: A longitudinal analysis. Indian Journal of Dermatology, 60(6), 566-572. https://doi.org/10.4103/0019-5154.169127

Tsaousi, G., Panidis, S., Stavrou, G., Tsouskas, J., Panagiotou, D., \& Kotzampassi, K. (2014). Prognostic indices of poor nutritional status and their impact on prolonged hospital stay in a Greek university hospital. BioMed Research International, 2014, 924270. https://doi. org/10.1155/2014/924270

Tschannen, D., Bates, O., Talsma, A., \& Guo, Y. (2012). Patient-specific and surgical characteristics in the development of pressure ulcers. American Journal of Critical Care, 21(2), 116-125. https://doi. org/10.4037/ajcc2012716

Walker, L. O., \& Avant, K. C. (2005). Strategies for theory construction in nursing (4th ed.). Upper Saddle River, NJ: Pearson-Prentice Hall.

Webster, J., Lister, C., Corry, J., Holland, M., Coleman, K., \& Marquart, L. (2015). Incidence and risk factors for surgically acquired pressure ulcers. Journal of Wound, Ostomy and Continence Nursing, 42(2), 138144, 137 pp. https://doi.org/10.1097/WON.0000000000000092

Yoshimura, M., lizaka, S., Kohno, M., Nagata, O., Yamasaki, T., Mae, T., ... Sanada, H. (2015). Risk factors associated with intraoperatively acquired pressure ulcers in the park-bench position: A retrospective study. International Wound Journal, 13(6), 1206-1213. https://doi. org/10.1111/iwj.12445

How to cite this article: Tschannen D, Anderson C. The pressure injury predictive model: A framework for hospitalacquired pressure injuries. J Clin Nurs. 2020;29:1398-1421. https://doi.org/10.1111/jocn.15171 